\title{
Short term displacements of marked pebbles in the swash zone: Focus on particle shape and size
}

ARTICLE in MARINE GEOLOGY · JUNE 2015

Impact Factor: 2.2 · DOI: 10.1016/j.margeo.2015.06.006

DOWNLOADS

20
VIEWS

18

4 AUTHORS:

\section{Edoardo Grottoli}

University of Ferrara

13 PUBLICATIONS 13 CITATIONS

SEE PROFILE

Paolo Ciavola

University of Ferrara

107 PUBLICATIONS 627 CITATIONS

SEE PROFILE
Duccio Bertoni

University of Ferrara

32 PUBLICATIONS 46 CITATIONS

SEE PROFILE

\section{Alessandro Pozzebon}

Università degli Studi di Siena

30 PUBLICATIONS 55 CITATIONS

SEE PROFILE 
1 Short term displacements of marked pebbles in the swash zone: focus on particle shape and size.

2 Edoardo Grottoli*, Duccio Bertoni*, Paolo Ciavola*, Alessandro Pozzebon**.

3 * Department of Physics and Earth Sciences, University of Ferrara, via Saragat 1, 44100 Ferrara, Italy

4 e-mail: grtdrd@unife.it

5
**Department of Information Engineering, University of Siena, via Roma 56, 53100 Siena, Italy

\section{Abstract}

In this paper, two short term experiments with tracers on a mixed beach are presented. The aim was to understand how the size and shape of pebbles can affect their transport under low energy conditions. Sediment transport was studied by means of RFID technology to univocally monitor every single marked pebble. A size subdivision of injected pebbles was conducted based on three classes ("Big" from -5.5 to -6.5 phi; "Medium", from -5 to -5.5 phi; and "Small", from -4.5 to -5 phi). Two recoveries were realised 6 and 24 hours after the injection. During a single day, the wave motion was very low in the first experiment and low to moderate in the second (never exceeding $0.4 \mathrm{~m}$ ). The results showed that discs are less dynamic than spheres but can cover greater distances. Regarding the sediment size, "Big" pebbles are less dynamic if compared to finer classes, and they move preferentially down the swash zone toward the step or do not move up-slope if already at the step. Very low and steady energy conditions facilitate cross-shore and offshore movement of pebbles, rather than a slight raise in wave height producing predominant longshore transport even with non-marginal displacements. Low to moderate energy conditions can also produce some trend displacement based on the pebble shape even though T-tests showed that shape was not statistically significant for pebble displacement. The displacements of "Medium" and "Small" sized pebbles show a statistical dissimilarity compared to the "Big" ones. To refine the velocity estimation necessary to initiate pebble movement, the threshold velocity formulas known up to now should involve the shape parameter, especially for the short term. Better knowledge of the relationship between the sediment's characteristics and dynamics is critical to forecast the durability of replenishment material and to establish the suitability of fill 
material relative to native beach material. Hence, a better understanding of the role of particle characteristics is necessary.

\section{Keywords}

Tracer; sediment transport; particle shape ; mixed beach; swash; gravel nourishments.

\section{Introduction}

Several hydrodynamic factors exert significant control on sediment transport for gravel and mixed sandgravel beaches, and these factors are still poorly understood. A comprehensive review of these forces was made in the recent past (Kirk, 1980; Mason and Coates, 2001; Buscombe and Masselink, 2006), but finding clear correlations between sediment characteristics and hydrodynamic agents still represents a hard challenge, especially in the swash zone. Gravel is not only larger, but usually varies over several orders of magnitude greater than beach sands (Buscombe and Masselink, 2006) and this characteristic creates extremely evident texture variations on coarse clastic beach surfaces, which cyclically raises the interest of researchers. After the early papers written mainly around the 1970s and 1980s (Bluck, 1967; Carr, 1969; McLean and Kirk, 1969; Carr et al., 1970; McLean, 1970; Carr, 1971; Gleason and Hardcastle, 1973; Orford, 1975; Kirk, 1980; Caldwell, 1981; Williams and Caldwell, 1988; Isla, 1993; Isla and Bujalesky, 1993), a renewed interest in sediment transport based on different coarse particle characteristics formed during the first decade of this millennium (Buscombe and Masselink, 2006; Ciavola and Castiglione, 2009; Bluck, 2011; Bertoni et al., 2012a). Textural mosaics of different clast shapes and sizes are common and different cross-shore size-shape zonations and modes of transport were demonstrated by many authors (Bluck, 1967; Orford, 1975; Williams and Caldwell, 1988; Isla, 1993; Ciavola and Castiglione, 2009; Hayes et al., 2010; Bluck, 2011), although the relative importance of size and shape in sorting sediment is yet to be resolved (Buscombe and Masselink, 2006). According to Kirk (1980), the most complex aspect of mixed beaches relates to sediment characteristics. Orford (1975) noted that the roles of size and shape cannot be easily separated; using both factors is therefore well-advised to establish the degree of pebble zonation on a 
beach before carrying out sedimentological characterization. Williams and Caldwell (1988) proposed a model wherein the influence of particle size is more important on the sorting of sediments when energy conditions are high, while particle shape predominates when energy conditions are low and cross-shore sediment transport prevails. Because most of the cited papers relate to meso- or macro-tidal beaches, except for Ciavola and Castiglione (2009), who provided insights on a micro-tidal beach, the aim of this work is to develop further ideas on this type of beach attempting to discriminate whether shape and size affect differentially pebble displacements in the swash zone under low-energy conditions . Furthermore, thanks to the RFID technology that enables the unambiguous identification of pebbles (Allan et al., 2006; Bertoni et al., 2010), it is possible to describe the movement of each individual particle according to its characteristics such as shape and size. This tracing technique, according to Van Wellen et al. (2000), is currently best suitable to obtain short-term transport rates on coarse-grained beaches.

\section{Regional setting}

The study area is a mixed sand-gravel beach located in Portonovo on the northern edge of the Conero Headland in the central sector of the Adriatic Sea (Figure 1). The beach is located on the eastern side of the village, it is approximately $500 \mathrm{~m}$ long and 20 to $60 \mathrm{~m}$ wide and is bounded by two boulder seawalls protecting historical buildings. The southern portion of the beach is wider and slightly embayed, whereas the northern part is narrower and straight. The beach was formed by a prehistoric landslide from the Conero Headland (Coccioni et al., 1997). In this sector of the Adriatic Sea, the littoral drift is directed northwards (Regione Marche, 2005), but this has no effect on Portonovo beach sediment transport because of its longshore boundaries. Cliff erosion is the only sediment source as there is no river input; the natural sediments consist of marls and limestones. The sediments vary from medium sand to cobble with a prevalent gravel fraction mainly formed by pebbles. The beach face typically slopes 0.2 , whereas the seabed seaward of the step is approximately 0.01 . The beach looks extremely heterogeneous regarding the surface sediment grain size: sand and scattered gravel accumulations cover the backshore whereas the gravel fraction usually occupies the swash zone, with granules and fine pebbles normally found on the berm and in the swash zone while cobbles and boulders are usually found on the step. According to the Jennings and Shulmeister (2002) 
classification of gravel beaches, Portonovo is a mixed sand and gravel beach (MSG), which is characterized by a complete intermixing of sandy and gravelly sediments (Figure 2).

Figure 1 goes approximately here

Figure 2 goes approximately here

In 2010, a replenishment made of alluvial material compatible with the original sediment was carried out by local authorities: pebbles and cobbles (4-100 mm in diameter) of limestone were used to contain beach erosion. The total amount of fill material deployed on Portonovo beaches between 2006 and 2011 was approximately $18500 \mathrm{~m}^{3}$ : most of it was unloaded on the western side of the village (Figure 1, personal communication by officers of the Regione Marche). The exact location and quantity of fill material released in the eastern side of the town are unknown. The average tidal range at spring tide is $40 \mathrm{~cm}$ in the Ancona area (Colantoni et al., 2003). The dominant winds come from the NE and SE, which correspond to the directions of the main storms. The typical wave heights are between 0.25 and $2 \mathrm{~m}$, with $20 \%$ of waves coming from SE and 15\% from NE (data recorded by the Ancona offshore wave buoy of ISPRA, Istituto Superiore per la Protezione e la Ricerca Ambientale, in the period 1999-2006, Figure 3).

Figure 3 goes approximately here

\section{Materials and methods}

Two tracer experiments were set up at the Portonovo beach. The first one was carried out in March 2012, and the second took place in April 2013. In both cases, the pebble displacement was investigated by means of RFID technology, which was initially designed for subaerial pebble tracking (Allan et al. 2006) and recently improved to work in the underwater environment (Bertoni et al. 2010). The technology is composed of two devices: an RFID radio signal antenna (or RFID reader) and a transponder (or tag). Each tag has an alphanumeric code that is required to unequivocally identify the pebble to which is coupled (Figure 4). The antenna is connected to a laptop, where the tag code is shown once a tracer is detected; in addition, an acoustic signal is emitted by the RFID reader as an additional warning sign of pebble detection. The electro- 
magnetic field generated by the antenna is similar to a sphere with a $40 \mathrm{~cm}$ radius, which represents the maximum detection range both underwater and in subaerial environments. According to Bertoni et al. (2010), the detection range could be higher using high frequency radio signals, but this would have basically impeded pebble detection underwater. The tracers were prepared by drilling a hole in each pebble to accommodate the tag (Figure 4); the hole was sealed with a waterproof resin, reducing the original weight by no more than $3 \mathrm{~g}$. The tagged pebbles were randomly collected from the beach surface (backshore and beach face), the only limitation being the size, which needed to be coarse enough to be drilled (Figure 4).

Figure 4 goes approximately here

\subsection{Experiment setup}

The two tracer experiments involved the same beach sector (Figure 1) and were carried out according to the same scheme. Marked pebbles were deployed in the swash zone along 29 cross-shore transects spaced $10 \mathrm{~m}$ (Figure 5A). Tracers were injected at 10:00 am and recovered after 6 and 24 hours. During both experiments, the wave characteristics were recorded by means of an InterOcean S4 directional wave gauge. The device was deployed on the bed seaward of the beach face to keep it underwater for the entire acquisition time (the instrument was deployed at $-1.5 \mathrm{~m}$ below Mean Sea Level, Figure 2A). Two time series of $20 \mathrm{~min}$ per hour were provided, measuring the water level and wave parameters at a frequency of $2 \mathrm{~Hz}$. For a water depth of $1.5 \mathrm{~m}$ the observational capability of the sensor is up to $0.004 \mathrm{~m}$. The uncertainty of measurement for wave direction is \pm 2 degrees.

The first tracer experiment was carried out in the early spring of 2012. The pebble population was sampled on March $17^{\text {th }}$, two weeks before the experiment: no significant topographic modifications occurred on the beach (Figure 6). At 10:00 am on March 29 ${ }^{\text {th }}, 145$ marked pebbles were injected in the swash zone according to the following order for each transect: one tracer was deployed on the fair weather berm crest; two tracers on the swash zone mid-point; and two tracers on the step crest. Five marked pebbles were injected along each profile without taking into account their size or shape (Figure 5B). 
131 The second tracer experiment was realised in mid-spring of 2013. Sampling took place on March $22^{\text {nd }}$, one

132 month before the experiment: no significant topographic modifications occurred on the beach in the time

133 span between the sampling and the injection (Figure 6). At 10:00 am on April $23^{\text {rd }}, 116$ tagged pebbles were

134 deployed on every profile following the scheme: one pebble on the fair weather berm crest; two tracers at the

135 swash zone mid-point; and one pebble on the step crest. No tracer subdivision in terms of shape was

136 conducted at the injection; they were only sorted by the grain size. The mean diameter considered for tracer

137 size subdivision was the b-axis, obtained from sieving at 0.5 phi. Three classes were considered: the "Small"

138 class, characterised by a mean diameter with values between -4.5 and -5 phi (coarse pebbles according to the

139 Udden-Wentworth grain size scale, 24 to $32 \mathrm{~mm}$ ); the "Medium" class, characterised by a mean diameter

140 with values between -5 and -5.5 phi (very coarse pebble according to the Udden-Wentworth grain size scale,

14132 to $48 \mathrm{~mm}$ ); and the "Big" size, characterised by a mean diameter with values between -5.5 and -6.5 phi

142 (very coarse pebble and small cobbles according to the Udden-Wentworth grain size scale, 48 to $96 \mathrm{~mm}$ ).

143 One "Small" pebble was injected on the fair weather berm crest, one "Small" tracer and one "Medium" tracer

144 were released on the swash zone mid-point, and one "Big" marked pebble was placed on the step crest. Four

145 marked pebbles were deployed on each profile (Figure 5C). This type of injection scheme was conceived to

146 understand whether a selective transport based on the different size of the tracers operates under low energy

147 conditions. Due to the frequent variation of the sediment grain size in the swash zone, two different pebble

148 sizes were released at its mid-point ("Small" and "Medium" classes) to better represent the most typical

149 grain sizes. The tracers deployed on the step were compatible with the sediment naturally present on that

150 portion of the beach; pebbles slightly coarser than those characterising the natural sediment berm were

151 injected on the fair-weather berm. Because of the logistic limitations of the drilling operation, a mean

152 diameter between -4.5 and -5 phi was the smallest size that could be drilled. A tracer distribution based on

153 shape and size is shown in Figure 7 for both experiments.

Figure 5 goes approximately here

Figure 6 goes approximately here 
Although the swash zone is subjected to continuous surface sediment changes, a likely beach sediment characterisation is shown in Table 1. Information on the beach sediments was obtained from surface sampling conducted the day before the experiments. Grain size analysis was carried out by dry-sieving the sediments at 1 phi mesh intervals for $15 \mathrm{~min}$.

Table1 goes approximately here

The tracer recovery campaigns were performed 6 and 24 hours after the injection for both experiments. The pebble displacements were measured by means of an RTK-DGPS (Trimble R6, instrument accuracy approximately $2 \mathrm{~cm}$ ). The tracer displacements were considered significant if greater than $0.5 \mathrm{~m}$ in XY to exclude shorter displacements wrongly caused by the antenna detection range (approximately $40 \mathrm{~cm}$ ).

\subsection{Mixing depth evaluation}

During the second experiment an evaluation of the mixing depth was carried out. Three piles of 15 painted pebbles were inserted at the back side of the fair-weather berm in order to appreciate the layer of sediments interested by wave reworking after one day (Figure 8A). Piles were located at three different sites along the beach: southern edge, mid sector and northern edge (Figure 8B). Disc shaped pebbles were chosen in order to build a more stable pile; they were painted in blue and numbered from 1 to 15 for each pile (the $15^{\text {th }}$ pebble at the pile bottom, the $1^{\text {st }}$ at the top, Figure $8 \mathrm{C}$ ). The resulting height was reckoned adding the $c$ axis of each pebble which was previously measured with a caliper.

Figure 8 goes approximately here

\subsection{Statistical analysis}

Statistical analysis was performed by means of T-tests and box plots on both the pebble shape and size. Box plots were used to describe the distributions of the pebble displacements according to shape and size separately and also to their combined effect. The recovery distributions after 6 and 24 hours were compared for each experiment. The size classes were divided according to the scheme used for the second experiment injection. The shape categories were established according to the Zingg diagram (Zingg, 1935). Each shape 
182 type was represented in the population used for the first experiment. Rods and blades were subordinate to

183 discs and spheres in terms of appearance. Due to their small quantity, the rods and blades were incorporated

184 with the discs to compare elongated shapes with spheres. In the second experiment, all the tracers belonged

185 to the sphere and disc shapes. Whether differential displacement was statistically significant between the

186 different shape and size classes of marked sediments (0.05 significance level) was tested. Because no size

187 discrimination was performed on the marked pebbles used in the first experiment (they all belong to the

188 "Big" class, which ranges from -5.5 phi to -6.5 phi), only the second experiment size data have been used for

189 the T-tests. T-tests were not used to analyse the combinational effect of shape and size given the scarce

190 quantity of data that would have resulted from an additional partition that takes into account both

191 characteristics.

192

3.4 Threshold of tracer motion

194 Estimations of the threshold wave orbital velocity for motion of pebble were computed and compared with the tracer displacements that were actually measured during both experiments. S4 data have been used to determine the threshold orbital velocity which was obtained using the graphical method of Soulsby (1997).

\section{Results}

\subsection{Wave climate and tracer recovery}

The wave motion during the first experiment was calm. Low energy was recorded throughout the entire experiment with an average significant wave height of $0.09 \mathrm{~m}$ (max value $0.15 \mathrm{~m})$ and a peak wave period of $4.3 \mathrm{~s}$. The wave direction was strongly variable: no dominant direction was recognisable even though the most frequent direction was NE (Figure 9). During the first experiment, tracer recovery after 6 hours was 99\%, which slightly decreased to $93 \%$ after 24 hours. Only a few tracers moved more than $0.5 \mathrm{~m}$ (17\% of the whole) after the first recovery, with a maximum displacement of $2.6 \mathrm{~m}$. Only $1 \%$ of the detected pebbles shifted over a different morphological feature. After 24 hours, $42 \%$ of the recovered tracers moved more 
than $0.5 \mathrm{~m}$ and the maximum measured displacement was $20 \mathrm{~m}$. Considering the population shifting to a different morphological feature, it increased at $17 \%$ after 24 hours. Cross-shore and offshore were the prevalent displacement directions. Basically, most of the tracers were dragged down the beach face, moving from the fair weather berm to the swash or the step zone (Figure 10B). Such a trend affected every shape because no differences in the displacement direction related to pebble shape were noted. The tracer displacements reached greater magnitudes on the northern sector of the beach with a stronger longshore component compared to the southern sector (Figure 10B).

The energy conditions during the second experiment were higher compared to those of the first one. An average wave height of $0.25 \mathrm{~m}$ ( $\max$ value $0.38 \mathrm{~m}$ ) with a peak wave period of $6 \mathrm{~s}$ was measured throughout the experiment. The significant wave height hovered at approximately 0.3 and $0.4 \mathrm{~m}$ during the first ten hours. The wave direction was basically stable within the ENE sector with a strong predominance from E, which lasted 18 hours (Figure 9). Pebble recovery was 34\% after 6 hours and increased to $47 \%$ after 24 hours. These lower percentages are connected to longer paths travelled by the tracers: the maximum displacements measured after 6 and 24 hours were, respectively, 52 and $54 \mathrm{~m}$. After the first recovery, 90\% of the detected pebbles exceeded the displacement threshold of $0.5 \mathrm{~m}$; a similar value was reached after 24 hours (89\%). The percentage of shifting to a different morphological feature was $38 \%$ after 6 hours and $49 \%$ after 24 hours. The tracers did not show any peculiar trend in terms of direction after 6 hours. A prevalent movement direction stands out after 24 hours: pebbles released at the swash zone's mid-point essentially split towards the up-slope and down-slope locations. All the pebbles moved from south to north, with shorter displacements in the southern part of the beach and greater displacements in the northern sector (Figure 10C, 10D). Disc-shaped pebbles travelled longer distances, and many of them ended up on the back of the berm. Spheres covered shorter paths after 24 hours and did not move landward of the fair-weather berm (Figure 10C, 10D). Regarding the size of the marked pebbles, "Small" and "Medium" classes seemed to move significantly even after 6 hours towards various directions (Figure 11A). All the sizes increased their displacements after 24 hours, even though the "Big" class was the least mobile (Figure 11A). Many "Small"sized tracers, initially located at the swash zone mid-point or on the fair-weather berm crest, reached the back of the fair-weather berm (Figure 11). "Medium"-sized pebbles essentially split from the swash zone midpoint either up-slope towards the berm or down-slope to the step crest. "Big"-sized tracers basically moved 
with short longshore paths in the southern part of the beach, never climbing up the swash zone slope. On the contrary, the "Big"-sized tracers in the northern sector showed longer displacements and in a few cases moved onshore, almost reaching the fair-weather berm (Figure 11).

Figure 9 goes approximately here

Figure 10 goes approximately here

Figure 11 goes approximately here

Regarding the second experiment it was also possible to analyse the combinational effect of shape and size.

"Big" class did not show any displacement difference between spheres and discs (Figure 12A, 12B).

"Medium"-sized tracers did not exhibit any peculiar movement during the 6 hour recovery (Figure 12C), while during the 24 hour recovery (Figure 12D) spheres moved preferentially offshore. "Small" class of tracers showed slight differences: especially 24 hours after the injection discs shaped pebbles moved behind the berm crest, reaching higher positions if compared to the "Small" spheres (Figure 12E, 12F).

Figure 12 approximately goes here

\subsection{Statistical analysis}

After the 6 hour recoveries of both experiments, all the size box plots are skewed to the right except for "Big"-sized pebbles (Figure 13A; 13B). The "Small" and "Medium" tracers moved significantly more compared to the "Big" ones, having a larger distribution interval compared to the biggest size (Figure 13B). Their median values are initially closer to the box bottom and then increase towards the end of the experiment. This does not happen to the "Big" class, which seems to be quite stable at low displacement values, especially for the median values. At the 6 hour recovery period, the "Medium" class has slightly longer displacements compared to the "Small" one. After 24 hours, the "Small"-sized tracers have the largest range, skewness and median values (without outliers) of any size class. The "Medium" class has the most stable range throughout the 24 hours, although the median value increases in the second recovery; on the other hand, the "Small" class has the largest stretch after one day, making it the most dynamic class (Figure 
13B). The box plots of pebble displacement show that the "Big" class is less susceptible to large movements, both 6 and 24 hours after tracer release. Although some "Big" pebbles moved up to $5 \mathrm{~m}$ from their initial position 24 hours after the injection, their median values are quite low and gravitate towards the bottom of the box (Figure 13A; 13B). "Big"-sized sediments seem to have a similar behaviour in both experiments.

Box plots of pebble shape are fairly different from one experiment to the other. In the first one, there is no remarkable difference between elongated and spherical shapes. After 6 hours, the spheres reach larger displacements compared to the elongated shapes, but they maintain roughly the same interval after 24 hours. The elongated shapes look more static at first but then show a quite similar to slightly larger range compared to the spheres after one day (Figure 14A). In each case, the median values are constantly close to the box bottom (Figure 14A). The intervals of the box plots are much larger in the second experiment (Figure 14B). Although the displacements are larger, the discs and spheres behave as they did during the first experiment. After 6 hours, the disc-shaped pebbles are less inclined to motion than the spheres. The spheres show slightly greater median values and larger intervals. After 24 hours, both shapes record larger displacements because of increased wave energy, but the discs have a wider range than the spheres. Furthermore, the disc box plot is skewed far to the right with a median value strongly adherent to the bottom. The sphere box plot seems to be more balanced with a more limited interval and a median value perfectly set in the middle of the interquartile range (Figure 14B).

Taking into account the combinational effect of shape and size some other peculiar behaviours of pebbles can be appreciated from box plots of the second experiment. "Big" spheres resulted more dynamic than discs since the first recovery. The larger displacements of "Big" spheres appeared fairly clear 24 hours after the injection, when most of them moved from the injection position of approximately $10 \mathrm{~m}$ (median value) and some of them up to $20 \mathrm{~m}$ (Figure 15A). The displacement interval of "Big" discs remained basically the same even after 24 hours, with the box steadily stuck at the bottom and maximum displacements of approximately 5 m (Figure 15A). "Medium"-sized discs recorded lower displacements than "Medium" spheres 6 hours after the injection. This situation was completely overturned after one day (Figure 15B). The interquartile range of "Medium" discs after 24 hours was the same produced by spheres of the same size already after 6 hours even though the median values differed consistently (Figure 15B). "Small”-sized 
spheres confirmed larger displacements if compared to the discs 6 hours after the injection. After one day the situation was overturned as already showed by the "Medium" class even though with larger displacements (Figure 15C).

T-tests on the pebble size data (Table 2) reveal that the "Big" tracers have significantly different displacements compared to the "Medium" and "Small" pebbles, except after 24 hours, where no substantial difference is noted. On the other hand, the "Small" and "Medium" tracer displacements are not significantly different either after the two recoveries. Accounting for the 6 hour recovery (Table 2), the "Big"-sized sediments show a significant dissimilarity compared to the other sizes. Statistically significant differences are not present in Table 3 according to the shape of the marked pebbles. There is no movement discrimination of the pebbles in terms of their shape for any recovery time, except for the first experiment among the discs and spheres 6 hours after the injection.

Figure 13 goes approximately here

Figure 14 goes approximately here

Figure 15 goes approximately here

Table 2 goes approximately here

Table 3 goes approximately here

\subsection{Mixing depth evaluation}

After one day two of the three blue pebble piles were completely dismantled. As showed in Table 4, only the "a" pile was not entirely wiped out because the $15^{\text {th }}$ pebble, initially placed at the pile bottom, was recovered in situ even after 24 hours. Therefore, a mixing depth of at least $30 \mathrm{~cm}$ was observed for the central and the northern sectors of the beach, whereas a slightly lower layer of sediments was reworked at the southern edge of the beach (about $25 \mathrm{~cm}$, Table 4).

Table 4 goes approximately here 
313 The estimation of the thresholds of motion using the graphical method of Soulsby (1997) gave the following 314 results. Considering the first experiment, the graphical method gives a value of $1.1 \mathrm{~ms}^{-1}$ for the "Big" class, 315 which was the only size class used at that experiment. For the second experiment, the Soulsby's method 316 provides a value of $1.2 \mathrm{~ms}^{-1}$ for the "Big"-sized pebbles, $1 \mathrm{~ms}^{-1}$ for the "Medium" class and $0.9 \mathrm{~ms}^{-1}$ for the 317 "Small" class (Figure 16). The graphical method of Soulsby (1997) resulted fairly close to the actual wave 318 orbital velocities measured by the $\mathrm{S} 4$ wave gauge (Figure 16).

\section{Discussion}

The tracer recovery percentages of the two experiments were quite different. This was determined by the different wave energy conditions, which could be considered very low for the first experiment (average significant wave height of $0.09 \mathrm{~m}$; max value $0.15 \mathrm{~m}$ ) and low to moderate for the second (average wave height of $0.25 \mathrm{~m}$; max value $0.38 \mathrm{~m}$ ). In the 2012 experiment, the recovery percentage was very high and the relocation of tracers onto a different morphological feature was fairly low. The downslope movement of the tracers from the berm crest was the most notable evidence of the first experiment. According to Bertoni et al. (2013), the process that caused the down dragging of pebbles is ascribed to the joint action of water level and swash fluxes. This tendency was not caused by higher wave energy, but by incessant swash action reworking the foreshore combined with the rise in the water level recorded during the night (Figure 9). The higher wave energy in the second experiment generated a quite different trend in the pebble displacements. Two pebbles with different sizes (one "Medium" and one "Small") were released at the swash zone mid-point.

Diversification in the displacement between those two sizes was not recorded, but a pronounced splitting of the tracers injected into the swash zone was found. This could be easily imputed to the slope and gravity actions, but it is not clear how some tracers went up to and over the berm while some others reached the step down slope. It is probable that a sufficiently energetic uprush moved the sediments up onto the berm, while 
an adequately energetic backwash dragged pebbles down towards the step. In both experiments, even though a main trend was recognisable after one day, not every part of the beach showed the same displacement patterns among the pebbles. The southern part of the beach, where the swash zone is steep and narrow, seems to be distinguished by shorter pebble displacements compared to the northern section. The latter is more exposed to wave action and looks like a "transfer zone", where a wider and milder sloping swash zone creates a more comfortable space for pebble transportation. A different level of beach exposure to wave motion emerged from the mixing depth evaluation: only the pebble pile inserted at the southern edge of the beach was not completely dismantled after one day, while at least $30 \mathrm{~cm}$ of sediments were surely removed by waves in the central and northern sectors. Similar values of mixing depth were measured on some steep Portuguese beaches by Ciavola et al. (1997). The authors found that the sand-mixing depth is equal to 0.27 times the wave height at breaking. A value of mixing depth of $22 \mathrm{~cm}$, comparable to ours results, was observed on the beach of Faro associated to a wave height at breaking of $0.80 \mathrm{~m}$ and a wave period of $7.0 \mathrm{~s}$. During our second experiment in Portonovo (wave height of $0.25 \mathrm{~m}$ and wave period of $6 \mathrm{~s}$ ) breakers were plunging directly on beachface as also confirmed by a surfing scale parameter of 2.7 . The beach face was sloping at 0.14 as averaged value which allows to use the formula proposed by Ciavola et al. (1997). The steepness and the high percentage of gravel which constitutes the beachface in Portonovo did not allow to build a proper structure where to place a pressure transducer measuring the actual wave parameters at breaking. Measurements provided by the S4 wave gauge are somehow related to wave conditions occurred immediately offshore the wave breaking and visual observations suggest that wave height at breaking was approximately $1 \mathrm{~m}$ which would correspond to a mixing depth value of $27 \mathrm{~cm}$ according to the relationship established by Ciavola et al. (1997). Ciavola et al. (1997) noted an anomalous value of mixing depth in a mixed sand and pebble beach in Hirono, Japan (Kraus et al., 1982). In the Japanese beach a small value of 3 $\mathrm{cm}$ was measured despite a wave height at breaking of almost $1 \mathrm{~m}$. Although Portonovo is more similar to Hirono from a sedimentological point of view, the mixing depth values estimated in our experiment are quite similar to those observed in Faro by Ciavola et al. (1997). Further investigation are needed on the interaction between sediment of different sizes (see sand versus pebbles or gravel) in order to evaluate more accurate measurements of mixing depth. 
In Portonovo the swash zone slope basically did not show any difference from south to north $(0.22-0.23$ in the first experiment and $0.13-0.16$ in the second one, Figure 6), but the higher exposure to wave action of the central and northern beach portions likely allowed sediments to travel longer distances in those areas. As confirmed by Bluck's works (Bluck 1967, 1999), if the beach system is in swash-alignment, the cross-shore transport can dominate regardless of wave energy (see Nash Point facies type). Portonovo beach does not show a perfect swash alignment and its slight embayment of the southern beach edge, which is also protected by an alongshore seawall, creates inconsistency on pebble displacements from south to north. Hence, longshore transport can easily occur in the more exposed areas of the beach (central and northern zone).

The results of the first experiment suggest that shape does not represent a discriminating factor for pebble movement: very low energy conditions combined with "Big"-sized tracers created a premise for pebble down dragging. Dissimilarities in the pebble displacements among different shapes of particles are more evident when analysing the outcome of the second experiment, where smaller tracers were investigated and higher wave energy occurred. This disparity seems to confirm what was already stated by McLean and Kirk (1969), that is, size is the primary factor controlling the sorting trends of sediments and shape is a second order factor. In the second experiment, many disc-shaped pebbles ended up on the back of the berm, while this did not happen to the spheres. As stated by Ciavola and Castiglione (2009) during an experiment conducted in a nearby sand-gravel mixed beach (Porto Recanati beach) under equivalent energy conditions, the uprush is able to drag large, flat pebbles up onto the beach face. Once the pebble reaches the berm, the backwash dissipates because of infiltration and the flattest pebbles are left there, while the more spherical ones roll down the slope. This was also observed by Bluck (1967) and Isla (1993) based on surface sampling and beach observations on macrotidal coarse-grained beaches; the same process was already described by Dobkins and Folk (1970) on some mixed beaches under low and high energy conditions (Table 5). Spherical and discoidal shapes behaved consistently during each experiment in terms of the displacement length. After 6 hours, the spheres moved further from the injection points than the discs, but after 24 hours the discs covered longer paths than the spheres. This trend was confirmed by box plots focused on the combined effect of shape and size except for the "Big"-sized pebbles. Wave motion recorded during the second experiment was not strong enough to entrain discs of bigger size, rather it was able to move spheres of the same size probably taking advantage of their capability to roll. Some authors found that discs have lower pivotability 
than spheres (Shepard and Young, 1964; Bluck, 1967) and the latter move more easily in traction (Bluck, 1967) by taking advantage of their spherical shape. The longer distances covered by discs after 24 hours do not mean that this shape is more dynamic compared to the spheres. As noted by Isla and Bujaleski (1993), spheres are preferentially set into "saltation", although the bed is dominated by discs, blades and rods, which means that spheres keep moving until they find a stable location to be incorporated into the sediments that constitute the beach (Caldwell, 1981), moving more quickly through the pores of the beach surface than other shapes (Bluck, 1967). The resulting difference in the behaviour of the two shapes at 6 and 24 hours cannot be imputed to an increase in the wave energy because higher waves occurred within 10 hours of the injection during the second experiment (the significant wave height remained between 0.3 and $0.4 \mathrm{~m}$ ), while the first experiment was characterised by quite low waves (average significant wave height of $0.09 \mathrm{~m}$; max value $0.15 \mathrm{~m}$ ). According to Orford (1975), the influence of shape depends not only on the wave energy but also on the wave phase and breaker type. The results from the shape displacements are not sufficient to say that there is a correlation between the shape and distance travelled by pebbles, as Carr (1971) already noted. Another aspect in need of in-depth investigation is the relationship between the shape of the pebbles and the characteristics of the surface over which they move (Carr et al., 1970; Caldwell, 1981): an irregular coarse bottom determines different types of pebble movements (Isla, 1993), and pebbles are preferentially entrained over sandy surfaces (Nordstrom and Jackson, 1993). Sherman et al. (1993) found that the distribution of shape and size facies is primarily controlled by location within the beach cusp systems. According to Bertoni et al. (2012b), the primary factor controlling the pebble displacement is the modification of incident waves induced by irregularities in the morphology of the sea bottom. A zonation of particle shape was not observed on the Portonovo swash zone, but shape very likely exerts an influence on pebble transport at least under low energy conditions and in the short term. As noted by Orford (1975), the roles of size and shape cannot be easily separated, and it is easier to use both factors to discern possible pebble zonation on a beach. The choice of focusing separately or combining the effect of size and shape on pebble movement should be done considering the energy conditions when the displacement takes place. Williams and Caldwell (1988) proposed a model wherein the influence of particle size is more important on sorting when energy conditions are high and particle shape predominates when energy conditions are low (Table 5). At the Portonovo beach, according to the size subdivision established only for the second experiment, only "Big" sized pebbles (-5.5 - 
-6.5 phi class) showed a different behaviour relative to the two finer classes. Pebbles of "Small" and "Medium" sizes (-4.5 - 5 phi and -5 - -5.5 phi classes, respectively) actually travelled greater distances than those belonging to the "Big" class; in addition, this difference in displacement was statistically significant, especially after 6 hours. The first 6 hours were characterised by moderate wave height (approximately 0.3 to $0.4 \mathrm{~m}$ up to 10 hours after the injection) that was not able to move "Big"-sized pebbles over the fair-weather berm. According to the paths of the marked pebbles, no relationship between their size and the elevation along the beach where they were detected was noted, which means that wave height is a subordinate factor controlling pebble displacement under very low energy conditions (first experiment) and under low-tomoderate energy conditions (second experiment). The swash zone slope, swash fluxes, run up levels and gravity play a major role in dragging down or moving up the pebbles along the swash zone. Coarser pebbles basically moved toward the step, not reaching the backshore under low-to-moderate energy conditions. As stated by Carr (1969), coarser material on the backshore is presumably "stranded" during longshore transport only under severe storm conditions. Later, Carr (1971) found a linear correlation between pebble size and the longshore movement in the short term, which becomes exponential in the long term. A sort of longshore size sorting caused by the vector imparted by the direction of the wave's approach can be recognised at the end of the second experiment, given that "Small"- and "Medium"-sized tracers moved farther from their injection positions compared to the "Big" pebbles (Figure 9; Figure 11). Because the conventional techniques (e.g., sediment samplings, beach observations) commonly provide an opportunity to recognise complex patterns on beach surfaces related to the size and shape of pebbles (McLean, 1970; Kirk, 1980), coarse tracer research needs to be supported by more sophisticated methods to improve the knowledge about the natural sieving of pebbles. Cross-shore transport was prevalent in the first experiment, while longshore paths were more evident in the second resulting from the higher energy conditions experienced. A short list of past studies concerning the relationship between pebble transport and their characteristics is presented in Table 5 .

Table 5 goes approximately here

Mixed beaches are dominated by swash action and the interaction between these flows and wave breakers (Kirk, 1980). Uprush-backwash systems are responsible for most of the activity on these beaches (Kirk, 1980). Kirk (1975) measured swash velocities on some mixed sand and gravel beaches: the mean velocity at 
447 the swash zone mid-point was $1.68 \mathrm{~ms}^{-1}$; the maximum swash velocity was $2.5 \mathrm{~ms}^{-1}$. The backwash velocities averaged $1.40 \mathrm{~ms}^{-1}$. Other studies observed a higher uprush velocity of $3.5 \mathrm{~ms}^{-1}$ on sandy steep beaches (Hughes et al., 1997; Masselink and Hughes, 1998). These velocities are comparable with the estimations conducted by the graphical method of Soulsby (1997) used in this study. As already noted by Kirk (1975), those velocity values are adequate to enable high transport rates for any sediment size on the foreshore. Because the majority of the injected pebbles recorded larger displacements after 24 hours in both experiments, the estimation of Soulsby (1997) seems to be plausible given that the threshold of motion for each size is closer to the wave orbital velocities computed from the S4 data. Because nearshore wave heights were used (the S4 was located very close to the shoreline, but not in the swash zone), the wave heights at the breaker line would be preferred to improve the accuracy of wave orbital velocity estimation. Williams and Caldwell (1988) provided insights on the relationship between pebble shape and swash flows. According to the authors, when swash velocities (either uprush or backwash) approach the critical threshold for transport, more easily suspended oblate sediments are thrown forward during the short-lived energy peak of the swash.

When non-marginal swash velocities occur, mass is more important than shape in determining sediment transport (cross-shore or alongshore) (Williams and Caldwell, 1988). Regarding the interaction between pebble size and swash fluxes, Isla (1993) supposed that an armoured deposit forms as flow decreases (during the backwash), producing an inverse grading of the sediment (coarser sediments over the finer ones). As expected and confirmed by many authors (Kirk, 1980; Van Wellen et al., 2000; Bertoni et al., 2013), the swash zone was the most dynamic part of the beach even under low energy conditions.

Sediment characteristics and sources are the key components of nourishment projects for several reasons. First of all, nourishment projects require a periodic maintenance that needs a planning of all the future recharging and monitoring stages of feeding material (transport, abrasion rate, loss rate) and mostly find an adequate sediment source. All beaches have specific sediment characteristics that fill material should meet, such as size, colour, roundness, sorting and mineralogical composition, but this task makes the research of fill material a hard challenge. At Portonovo beach, the ideal fill material for nourishment purposes should be formed by sphere-shaped pebbles. It is fairly clear that spherical and well rounded material is not easy to 
deposition and in a more consistent way compared to a similar amount of discoidal pebbles. Furthermore, during storms, discs could be transported towards the beach edges and be unlikely reworked by normal wave motion. An ideal beach constituted just by spherical pebbles would always keep moving with no "permanent" erosive or accumulation areas, always responding in an active way to any energy condition. Regarding the size to be adopted for a pebble replenishment, a dimension comprised between -5.5 and -6.5 phi ("Big" size, very coarse pebble and small cobbles according to the Udden-Wentworth grain size scale, 48 to $96 \mathrm{~mm}$ ) is to avoid given its low mobility. "Big"-sized pebbles could be used to build step feature or anything that should be more stable. "Medium" and "Small"-sized pebbles (coarse and very coarse pebbles, 4.5 to -5.5 phi or 24 to $48 \mathrm{~mm}$ according to the Udden-Wentworth grain size scale) should be preferred for feeding the beach in its swash and emerged areas in order to keep the system free to actively interact with wave energy. Some authors remarked the loss of nourishment gravel after a certain time since the end of replenishment (Takagi et al., 2000; Maddrell, 1996). Harley et al. (2014) analysed in a nearby beach (Sirolo, San Michele - Sassi Neri) how a gravel nourishment responded to beach rotation processes which also affect Portonovo beach: therefore, a better understanding of sediment characteristics is crucial for future nourishment purposes. The use of natural sediment as fill material is always recommended, trying to meet as more as possible the characteristics of native material.

\section{Conclusions}

The study presented here shows an original contribution to the understanding of the role of pebble characteristics on controlling sediment transport. Discs can cover greater distances than spheres but are less dynamic. Once lifted and shifted by swash flows, the discs can travel long paths, reaching a stable location distinguished by feeble forces under low wave energy conditions (e.g., the rear of the fair-weather berm or slope break between the swash zone and the beach step).

"Big"-sized pebbles (-5.5 to -6.5 phi) are less dynamic compared to the finer classes ("Medium", -5 to -5.5 phi; "Small", -4.5 to -5 phi). They are not able to reach the back of the fair-weather berm if initially deployed at the step crest but can be easily dragged down to the swash or step zone if released on the berm crest, even 
501 under very low energy conditions. Nevertheless the "Big"-sized spheres appear to be slightly more dynamic 502 than discs of the same size.

503 There is no statistical relationship between the shape of the pebbles and their displacements, although 504 different shapes respond to different forces. "Big"-sized sediments seem to have a similar behaviour in both 505 experiments, which is significantly different from that of the "Medium" and "Small" classes. Further 506 investigations focusing on particle shape are needed to identify the possible primary factors that control 507 pebble movement (e.g., divergences in beach slope, pebble size, beach exposure, and beach surface 508 sediment).

509 Very low energy conditions create a premise for the cross-shore and offshore movement of pebbles. In that 510 case, wave height has a marginal role on pebble movement, while beach orientation in relation to the 511 dominant wave direction seems to have a major role. A slight raise in wave height produces a predominant 512 longshore transport even with non-marginal displacements. Furthermore, low to moderate energy conditions 513 allow some trend displacement based on pebble shape.

514 Actual measurements of swash velocities, which are able to initiate pebble migration, should be obtained to 515 improve threshold velocity formulas, which currently do not include any shape parameter. It is believed that 516 shape can be a discriminant factor for the transportation of sediments having a mean size between the coarse 517 and very coarse pebble size classes (from 16 to $64 \mathrm{~mm}$, respectively), at least under low energy conditions.

518 Because artificial replenishments made with coarse-clastic material have become more popular in recent 519 years, studies dealing in the shape, size and abrasion of pebbles have important implications. A good 520 knowledge of the relationship between the textural characteristics of sediments and their dynamics is crucial 521 to establish the suitability of fill material relative to native beach material. Rising costs are inevitable in the 522 case of replenishment with gravel or coarse-clastic material when not naturally present in huge quantities 523 (i.e., Adriatic Sea). Under these circumstances, the fill material is obtained from quarry processing. Quarry 524 waste needs artificial crushing to obtain the required sediment size, which should be as close as possible to 525 the native sediment. For nourishment purposes a spherical shape and a size comprised between -4.5 and -5.5 526 phi (24 to $48 \mathrm{~mm}$ ) should be preferred since spheres of that size are more dynamic than discs and tend to 
527 prevent the creation of permanent areas in erosion or in strong accumulation on the beach. Thus, a better

528 understanding of the role of particle characteristics is needed.

\section{Acknowledgements}

We are thankful to Giovanni Salcioli, Gino Brambilla, Mitch Harley of the University of Ferrara and Prof. Javier Benavente of the University of Cadiz for their support during the fieldwork. Thanks to Prof. Nancy Jackson of the New Jersey Institute of Technology for her precious advices in the early stage of this article. We are also thankful to Regione Marche - P.F. Difesa della Costa for following and supporting our research.

\section{References}

Allan, J.C., Hart, R., Tranquilli, J.V., 2006. The use of Passive Integrated Transponder (PIT) tags to trace cobble transport in a mixed sand and-gravel beach on the high-energy Oregon coast, USA. Marine Geology 232, 63-86.

Bertoni, D., Sarti, G., Benelli, G., Pozzebon, A., Ragueseo, G., 2010. Radio Frequency Identification (RFID) technology applied to the definition of underwater and subaerial coarse sediment movement. Sedimentary Geology 228, 140-150.

Bertoni, D., Sarti, G., Benelli, G., Pozzebon, A., 2012a. In situ abrasion of marked pebbles on two coarse clastic beaches (Marina di Pisa, Italy). Italian Journal of Geoscience 131, 205-214.

Bertoni, D., Sarti, G., Benelli, G., Pozzebon, A., Raguseo, G., 2012b. Transport trajectories of "smart” pebbles on an artificial coarse-grained beach at Marina di Pisa (Italy): Implications for beach morphodynamics. Marine Geology 291-294, 227-235.

Bertoni, D., Grottoli, E., Ciavola, P., Sarti, G., Benelli, G., Pozzebon, A., 2013. On the displacement of marked pebbles on two coarse-clastic beaches during short fair-weather periods (Marina di Pisa and Portonovo, Italy). GeoMarine Letters 33, 463-476. 
551 Bluck, B.J., 1967. Sedimentation of beach gravels: examples from South Wales. Journal of Sedimentary 552 Petrology 37, 128-156.

553 Bluck, B.J., 1999. Clast assembling, bed forms and structure in gravel beaches. Trans. Roy. Soc. Edinb.

554 Earth Sci. 89, 291-323.

555 Bluck, B.J., 2011. Structure of gravel beaches and their relationship to tidal range. Sedimentology 58, 9945561006.

557 Buscombe, D., Masselink, G., 2006. Concepts in gravel dynamics. Earth-Science Reviews 79, 33-52.

558 Caldwell, N.E., 1981. Relationship between tracers and background beach material. Journal of Sedimentary $559 \quad$ Research 51, 1163-1168.

560 Carr, A.P., 1969. Size grading along a pebble beach: Chesil Beach, England. Journal of Sedimentary 561 Petrology 39, 297-311.

562 Carr, A.P., Gleason, R., King, A., 1970. Significance of pebble size and shape in sorting by waves. 563 Sedimentary Geology 4, 89-101.

564 Carr, A.P., 1971. Experiments on longshore transport and sorting of pebbles; Chesil Beach, England. Journal 565 of Sedimentary Research 41, 1084-1104.

566 Ciavola, P., Taborda, R., Ferreira, O., Dias, J.A., 1997. Field observations of sand-mixing depths on steep 567 beaches. Marine Geology 141, 147-156.

568 Ciavola, P., Castiglione, E., 2009. Sediment dynamics of mixed sand and gravel beaches at short timescales. 569 Journal of Coastal Research S.I. 56, 1751-1755.

570 Coccioni, R., Moretti, E., Nesci, O., Savelli, D., Tramontana, M., Veneri, F., Astracedi, M., 1997. Carta 571 geologica con itinerari geologico-escursionistici, Parco Naturale del Conero, scala 1:20.000. Selca Edizioni, 572 Firenze.

573 Colantoni, P., Mencucci, D., Baldelli, G., 2003. Idrologia e idraulica costiere processi litorali attuali e 574 deposizione dei sedimenti. In: Coccioni, R., (Eds.), Verso la gestione integrata della costa del Monte San 
575 Bartolo: risultati di un progetto pilota, Quaderni del Centro di Geobiologia dell’Università degli Studi di 576 Urbino, Urbania, 15-37.

577 Dobkins, J.E., Folk, R.L., 1970. Shape development on Tahiti-nui. Journal of Sedimentary Petrology 40, $578 \quad 1167-1203$.

579 Gleason, R., Hardcastle, P.J., 1973. The significance of wave parameters in the sorting of beach pebbles. 580 Estuarine and Coastal Marine Science 1, 11-18.

581 Harley, M.D., Andriolo, U., Armaroli, C., Ciavola, P., 2014. Shoreline rotation and response to nourishment 582 of a gravel embayed beach using a low-cost video monitoring technique: San Michele-Sassi Neri, Central 583 Italy. Journal of Coastal Conservation 18, 551-565.

584 Hayes, M.O., Michel, J., Betenbaugh, D.V., 2010. The intermittently exposed, coarse-grained gravel beaches 585 of Prince William Sound, Alaska: comparison with open-ocean gravel beaches. Journal of Coastal Research $586 \quad 26,4-30$.

Hughes, M.G., Masselink, G., Brander, R.W., 1997. Flow velocity and sediment transport in the swash zone 588 of a steep beach. Marine Geology 138, 91-103.

Isla, F.I., 1993. Overpassing and armouring phenomena on gravel beaches. Marine Geology 110, 369-376. 186, 211-228.

Kirk, R. M., 1975. Aspects of surf and runup processes on mixed sand and gravel beaches. Geografiska Annaler. Series A. Physical Geography 57, 117-133.

Kirk, R.M., 1980. Mixed sand and gravel beaches: morphology, processes and sediments. Progress in 597 Physical Geography 4, 189-210. 
598 Kraus, N.c., Isobe, M., Igarashi, H., Sasaki, T.O., Horikawa, K., 1982. Field experiments on vertical mixing 599 of sand in the surf zone. Proceedings of the $18^{\text {th }}$ International Coastal Engeneering Conference, ASCE, New 600 York, 970-988.

601 Maddrell, R.J., 1996. Managed coastal retreat, reducing flood risks and protection costs, Dungeness Nuclear 602 Power Station, UK. Coastal Engineering 28, 1-15.

603 Mason, T., Coates, T.T., 2001. Sediment transport processes on mixed beaches: a review for shoreline 604 management. Journal of Coastal Research 17, 645-657.

605 Masselink, G., Hughes, M.G., 1998. Field investigations of sediment transport in the swash zone. 606 Continental Shelf Research 19, 1179-1199.

607 McLean, R.F., Kirk, R.M., 1969. Relationships between grain size, size-sorting, and foreshore slope on 608 mixed sand-shingle beaches. New Zealand Journal of Geology and Geophysics 12, 138-155.

609 McLean, R.F., 1970. Variations in grain-size and sorting on two Kaikoura beaches. New Zealand Journal of 610 Marine and Freshwater Research 4, 141-164.

611 Nordstrom, K.F., Jackson, N.L., 1993. Distribution of surface pebbles with changes in wave energy on a 612 sandy estuarine beach. Journal of Sedimentary Petrology 63, 1152-1159.

613 Nunny, R.S., Chillingworth, P.C.H., 1986. Marine dredging for sand and gravel. HMSO, London.

614 Orford, J.D., 1975. Discrimination of particle zonation on a pebble beach. Sedimentology 22, 441-463.

615 Regione Marche, 2005. Studi, indagini, modelli matematici finalizzati alla redazione del piano di difesa della 616 costa. Bollettino Ufficiale della Regione Marche 21, 4199-4675.

617 Shepard, F.P., Young, R., 1961. Distinguishing between beach and dune sands. Journal of Sedimentary 618 Petrology 31, 196-214.

619 Sherman, D.J., Orford, J.D., Carter, R.W.G., 1993. Development of cusp-related, gravel size and shape facies 620 at Malin Head, Ireland. Sedimentology 40, 1139-1152. 
621 Smith, M.R., Collis, L., 1993. Aggregates. Sand, gravel and crushed rock aggregate for construction purpose.

622 The Geological Society, London.

623 Soulsby, R., 1997. Dynamics of marine sands: a manual for practical applications. Thomas Telford, London, 624272.

625 Takagi, T., Satoh, S., Yamamoto, K., Sakurai, W., Murano, U., Atsuzaka, Y., Ding Y., 2000. Performance of 626 gravel nourishment for erosion control at Fuji coast. Coastal Engineering, 3333 - 3344.

627 Van Wellen, E., Chadwick, A.J., Mason, T., 2000. A review and assessment of longshore sediment transport 628 equations for coarse-grained beaches. Coastal Engineering 40, 243-275.

629 Williams, A.T., Caldwell, N.E., 1988. Particle size and shape in pebble-beach sedimentation. Marine 630 Geology 82, 199-215.

631 Zingg, T., 1935. Beitrag zur Schotteranalyse. Schweiz. Mineral. Petrogr. Mitt 15, 39-140.

\section{List of Figures}

Figure 1 - Study site.

Figure 2 - Overall view of the beach durign the first (A) and the second experiment (B).

Figure 3 - Long term wave data from 1999 to 2006 provided by regioanl wave buoy of ISPRA Istituto Superiore per la Protezione e la Ricerca Ambientale.

Figure 4 - Example of marked pebble. Cylinder glass tag (A). Drilled pebbles of "Medium" size (B).

Figure 5 - Experiment setup showing the device and tracer positions over an elevation surface (elevation

641 and second experiment (C).

642 Figure 6 - Beach profile comparison between the tracer sampling and the tracer injection for both the experiments 
644 Figure 7 - Distribution of tracer used in the experiments according to their shape and size.

645 Figure 8 - Scheme of the mixing depth valuation conceived during the second experiment (A). Locations of 646 pebble piles on the three crucial beach points (B). Painted pebbles of disc shape used for the mixing depth 647 valuation $(\mathrm{C})$

648 Figure 9 - Wave climate during both experiments recorded by an S4 directional wave gauge.

649 Figure 10 - Tracer displacement in terms of shape: first experiment 6 hour displacements (A); first 650 experiment 24 hour displacements (B); second experiment 6 hour displacements (C) and second experiment 65124 hour displacements (D).

652 Figure 11 - Tracer displacement in terms of size (only $2^{\text {nd }}$ experiment): 6 hour displacements (A) and 24 hour 653 displacements (B).

654 Figure 12 - Tracer displacement based on the combined effect of size and shape (only $2^{\text {nd }}$ experiment): "Big" 655 class displacements 6 hours (A) and 24 hours (B) after the injection; "Medium" class displacements 6 hours 656 (C) and 24 hours (D) after the injection; and "Small" class displacements 6 hours (E) and 24 hours (F) after 657 the injection.

658 Figure 13 - Box plots showing the displacement magnitude after the 6 and 24 hour recoveries according to 659 the size subdivision of the tracers. Box plots referring to the first experiment (B) and box plots referring to 660 the second experiment (B): here, a size discrimination was taken into account prior to pebble injection.

661 Figure 14 - Box plots showing the pebble displacement magnitude after 6 and 24 hours according to the 662 shape subdivision of the tracers. A) box plots referring to the first experiment, where the elongated shapes 663 are joined together ( $\mathrm{D}=$ Disc, $\mathrm{B}=$ Blade, $\mathrm{R}=\mathrm{Rod}$ ); and $\mathrm{B}$ ) box plots referring to the second experiment, 664 where only the disc and sphere shapes were present.

665 Figure 15 - Box plots showing the pebble displacement magnitude after 6 and 24 hours based on the 666 combined effect of size and shape. A) "Big"-sized discs and spheres comparison; B) "Medium"-size discs 667 and spheres comparison; C) “Small”-sized discs and spheres comparison. 
668 Figure 16 - Threshold of motion of the marked pebbles estimated by the graphic method of Soulsby (1997)

669 for the $1^{\text {st }}(\mathrm{A})$ and the $2^{\text {nd }}(\mathrm{B})$ experiment.

670

671

672 List of Tables

673 Table 1 - Mean diameter comparison between the natural beach sediment and marked pebbles. The averaged

674 values are in $\mathrm{mm}$ for each morphological feature. No step crest samples were collected during the second 675 experiment.

676 Table 2 - Probability values calculated by means of T-tests. The pebble displacements measured for different

677 sizes are compared. The bold numbers represent a significant difference between the two categories

678 considered in each row. A significance level of $\mathrm{P}<0.05$ was used.

679 Table 3 - Probability values calculated by means of T-tests. The pebble displacements measured for different

680 shapes are compared. The bold numbers represent a significant difference between the two categories

681 considered in each row $(\mathrm{D}=$ Discs; $\mathrm{B}=$ Blades; $\mathrm{R}=$ Rods; $\mathrm{S}=$ Spheres $)$. A significance level of $\mathrm{P}<0.05$ was

682 used.

683 Table 4 - Mixing depth results for the three beach locations.

684 Table 5 - List of the most recent studies on the role of particle size and shape on coarse-clastic and mixed 685 beaches. 

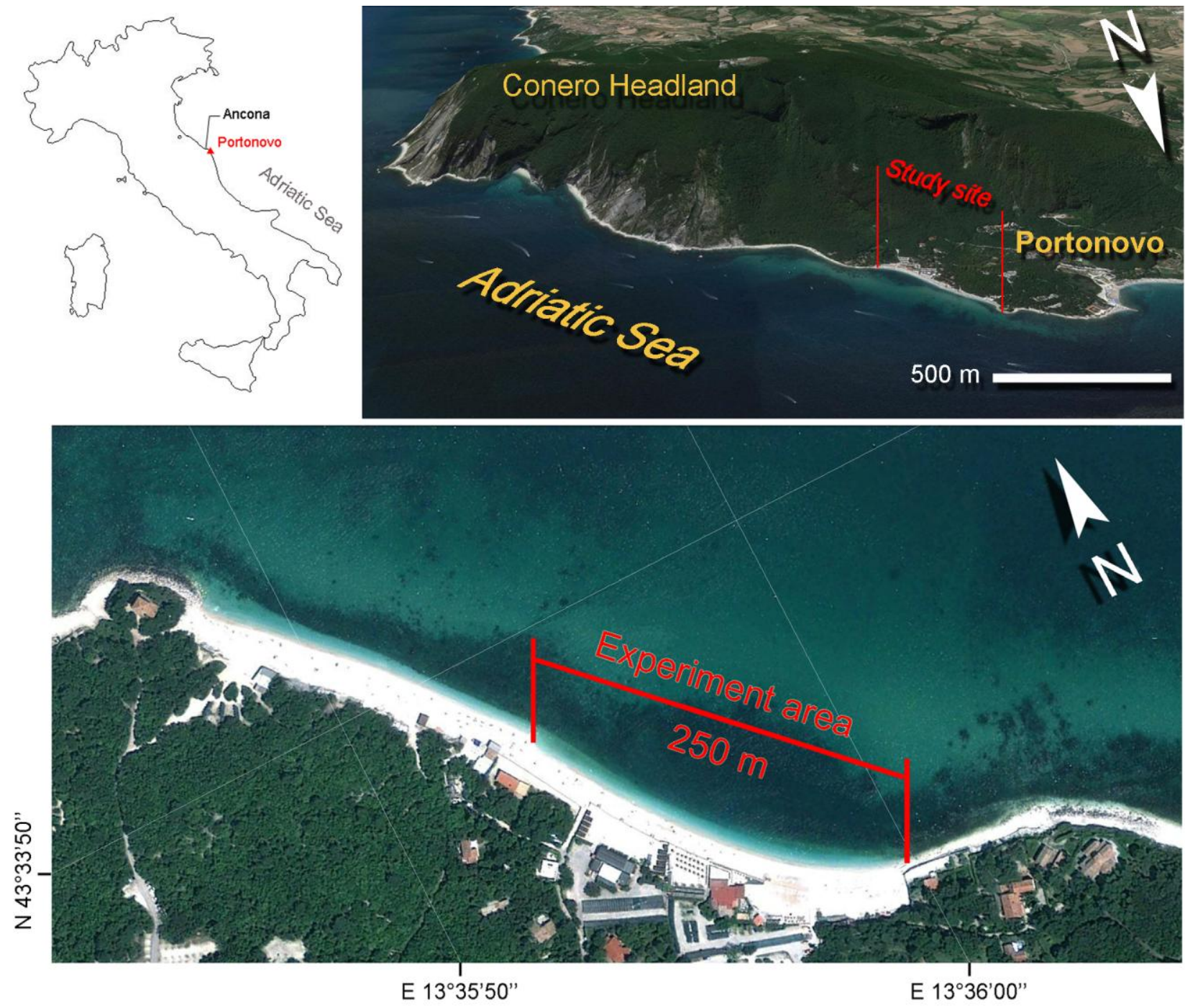

692

Figure 1

693
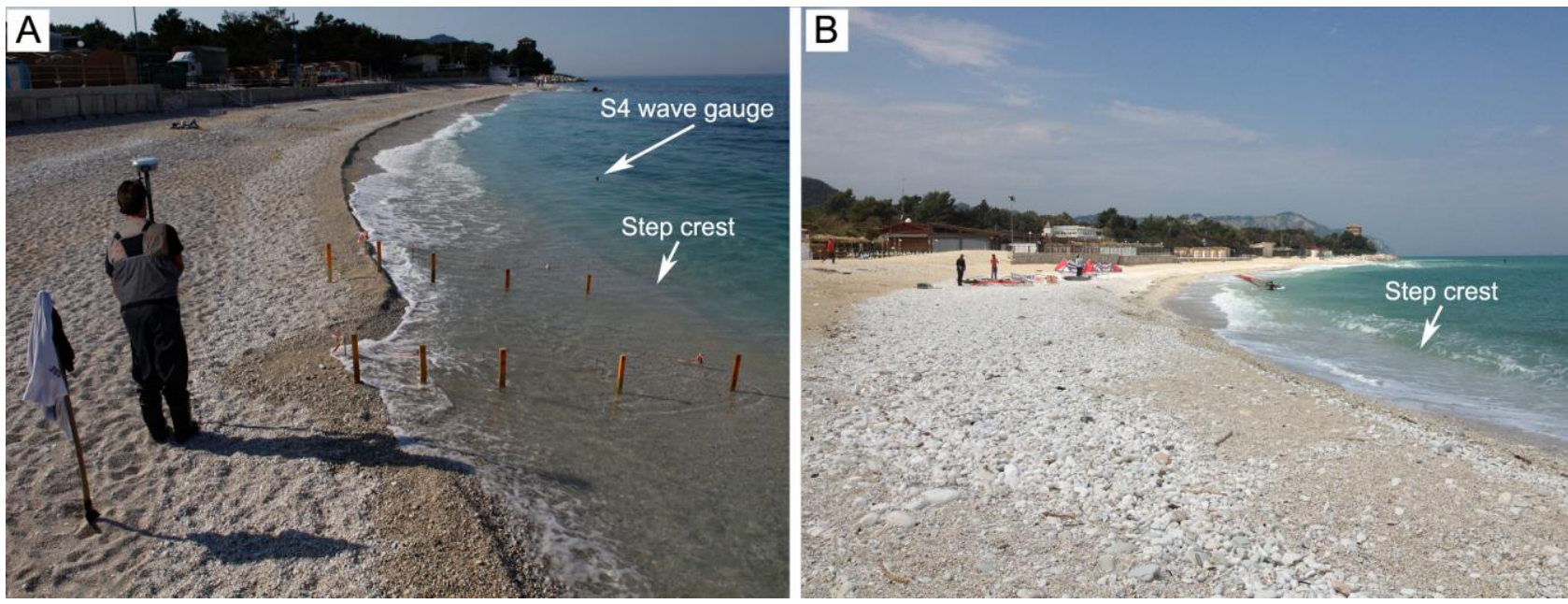


\section{Ancona offshore buoy}

\section{9 - 2006}

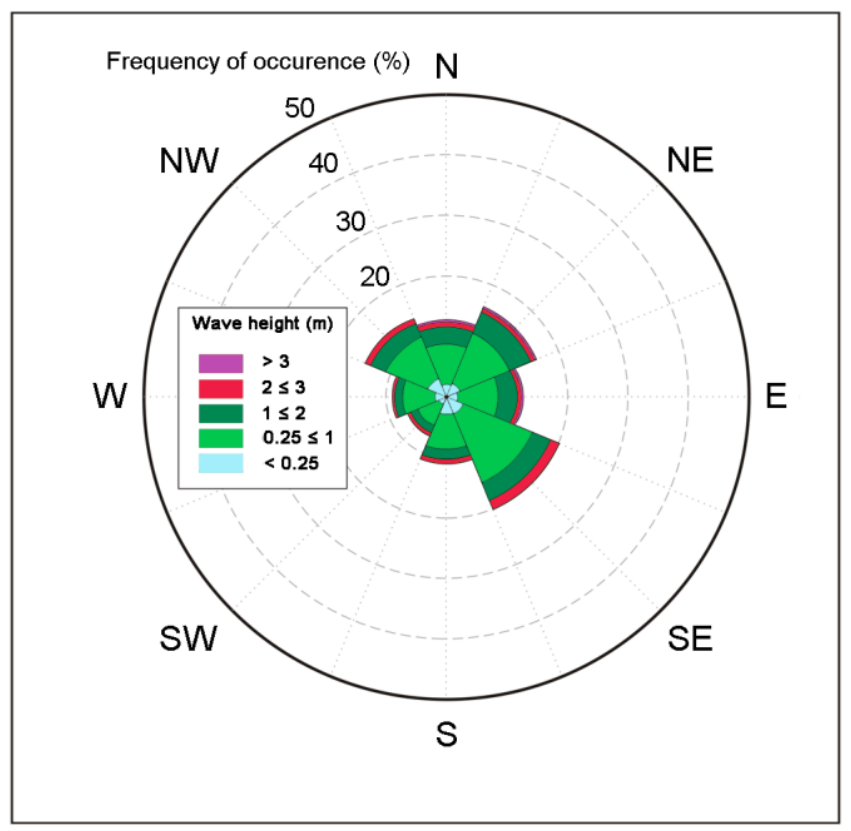

697

698

699

700

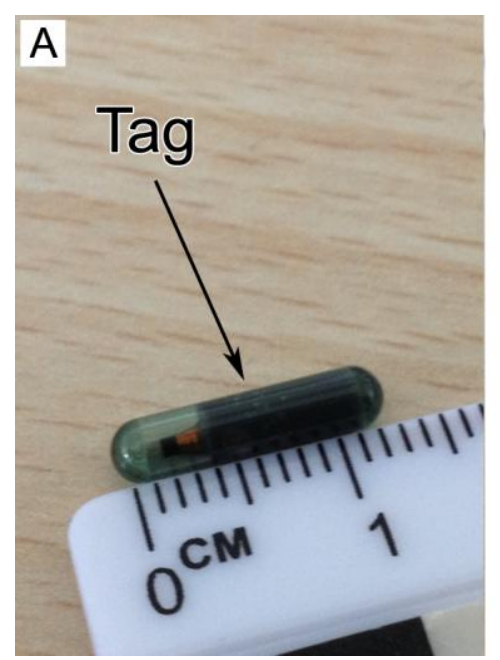

701

702

Figure 3

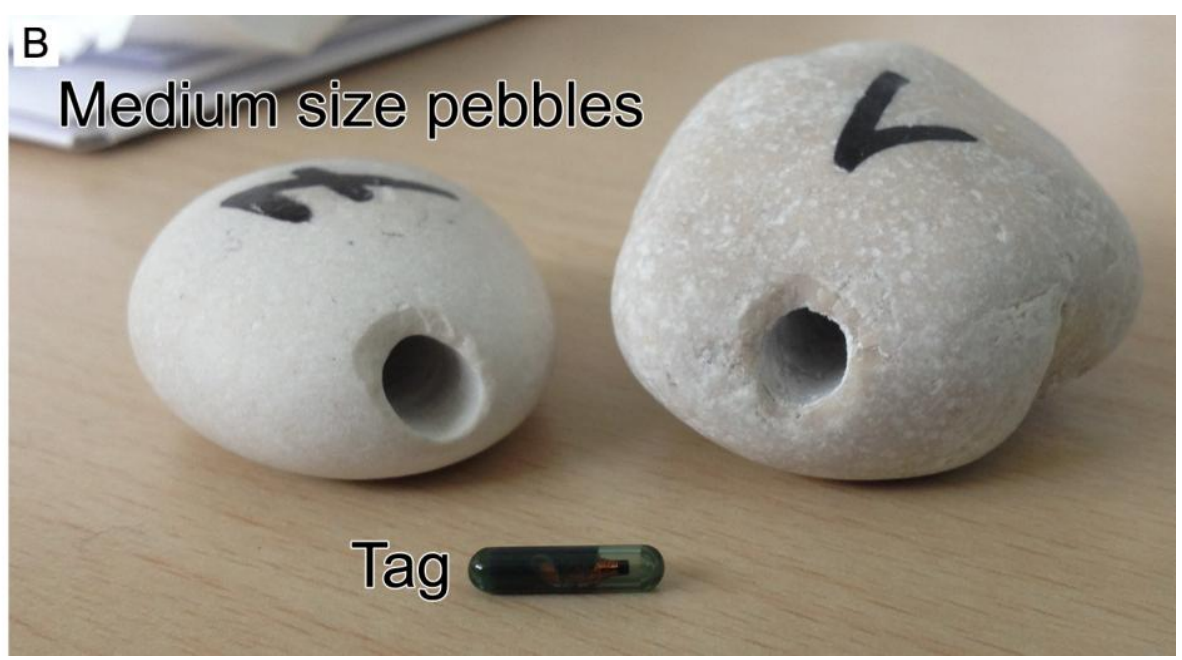

Figure 4 


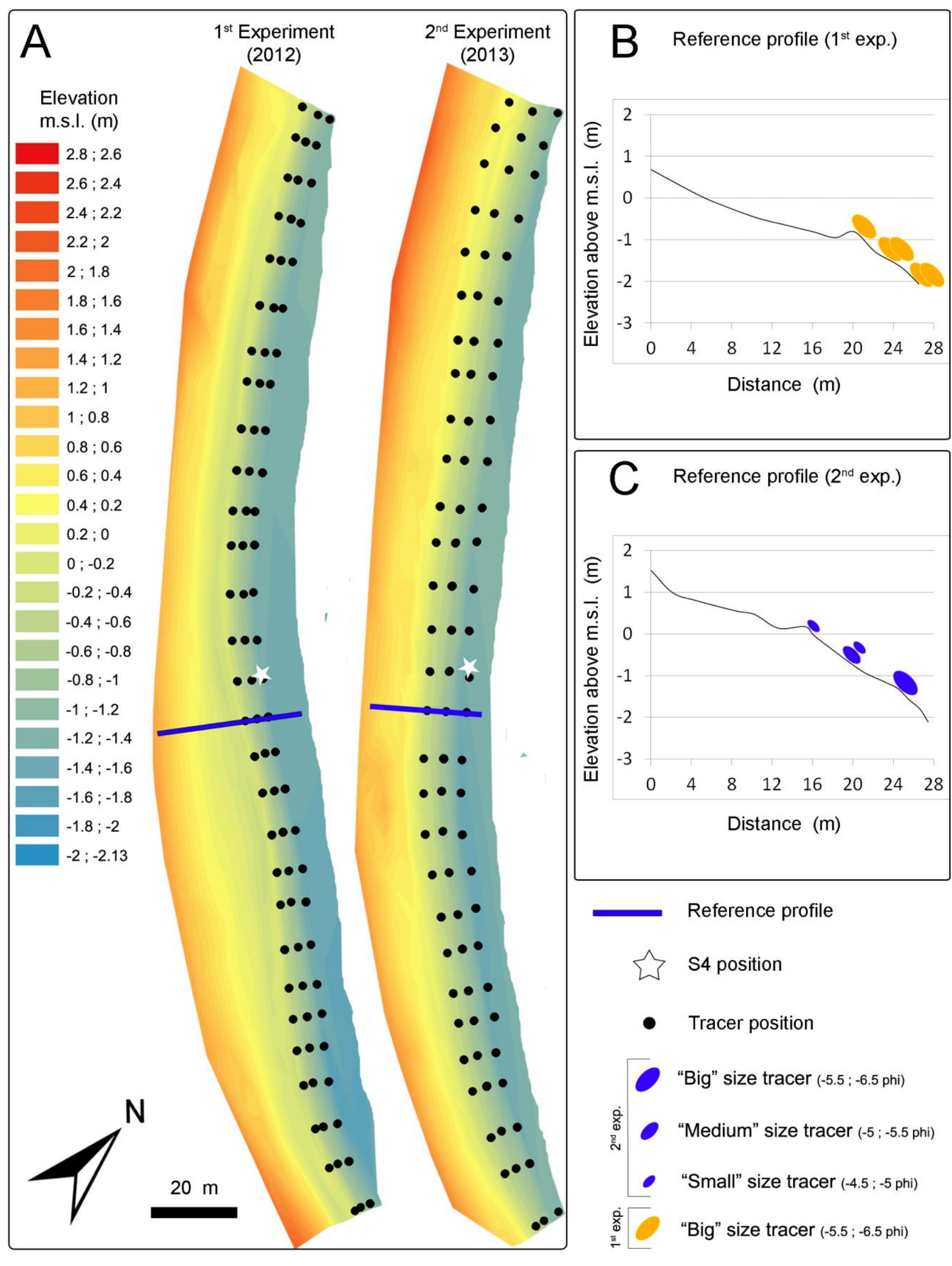




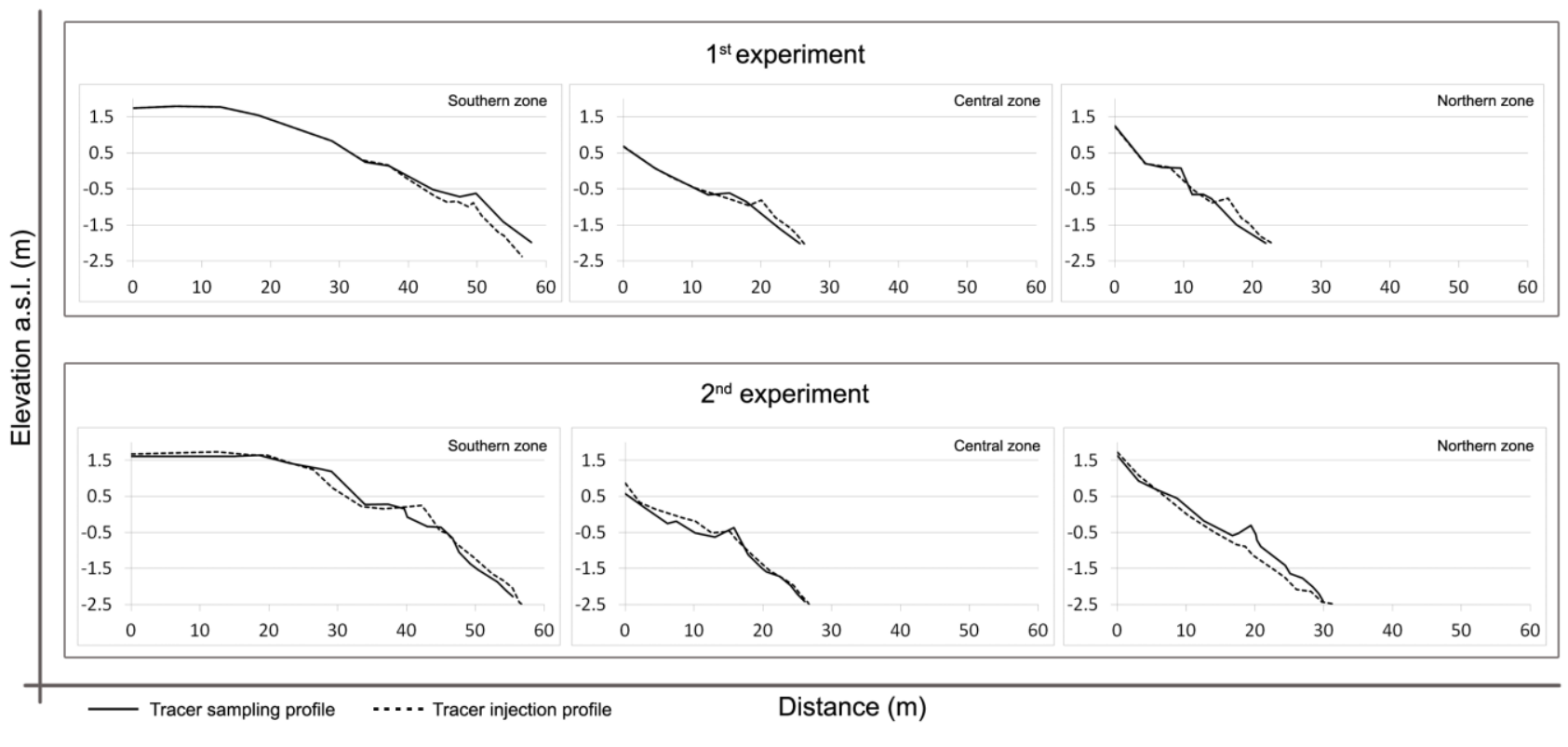


$1^{\text {st }}$ experiment

$2^{\text {nd }}$ experiment

Shape
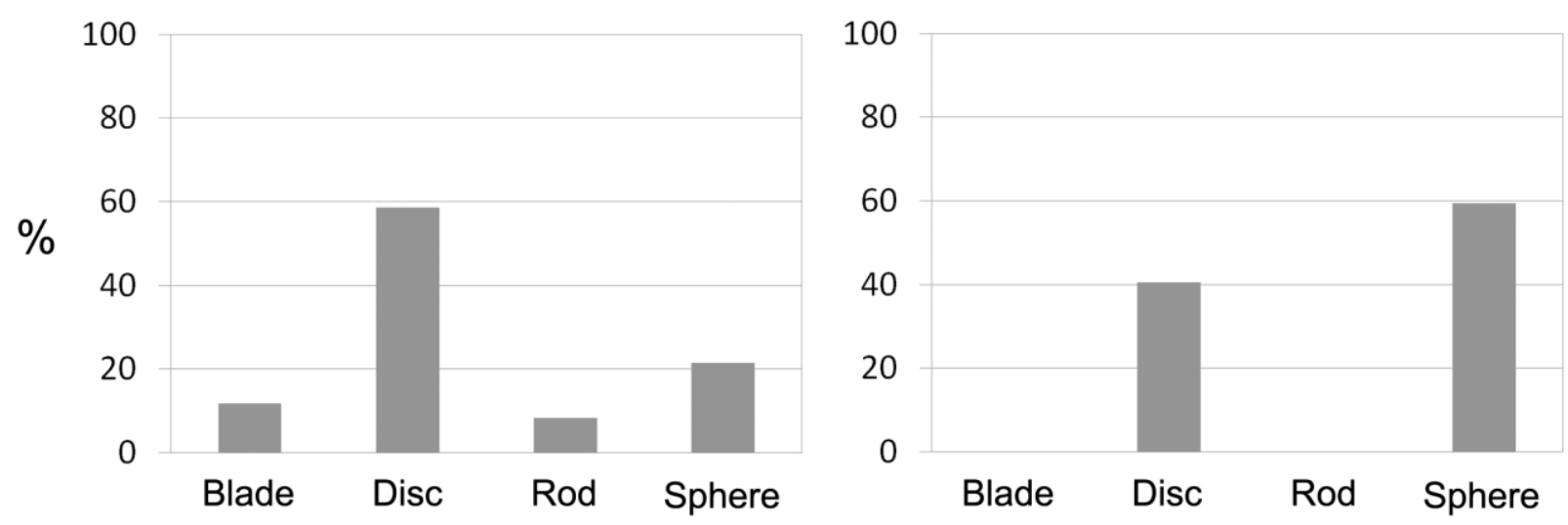

Size
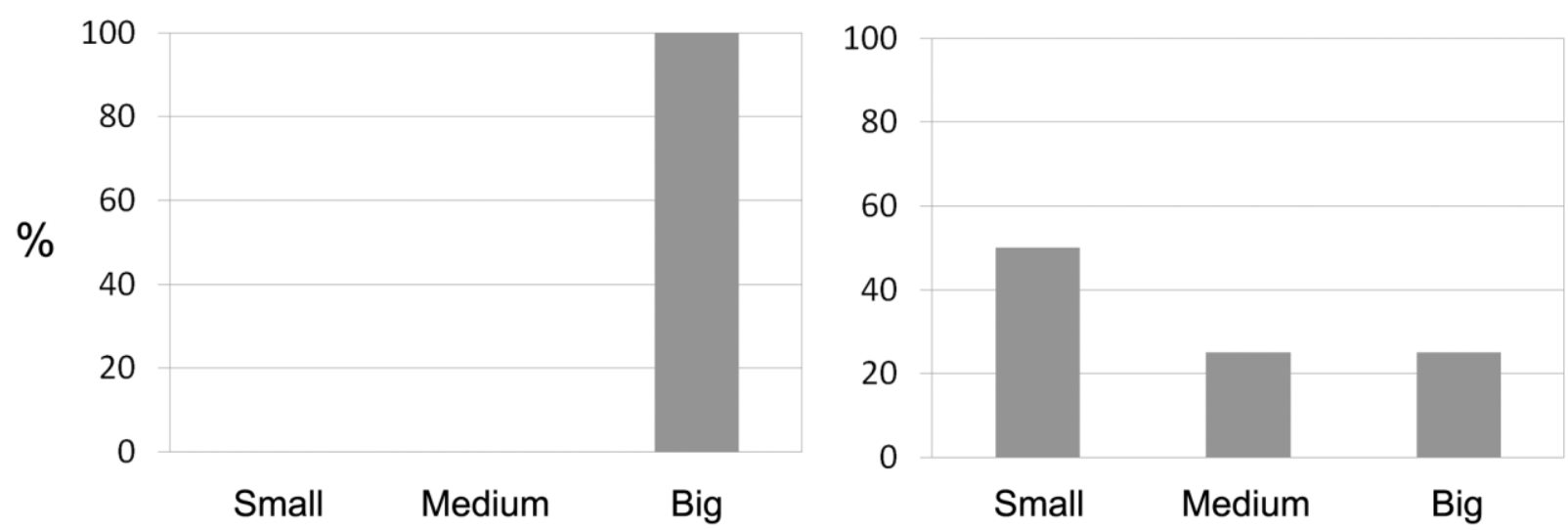

709

710

Figure 7

711 


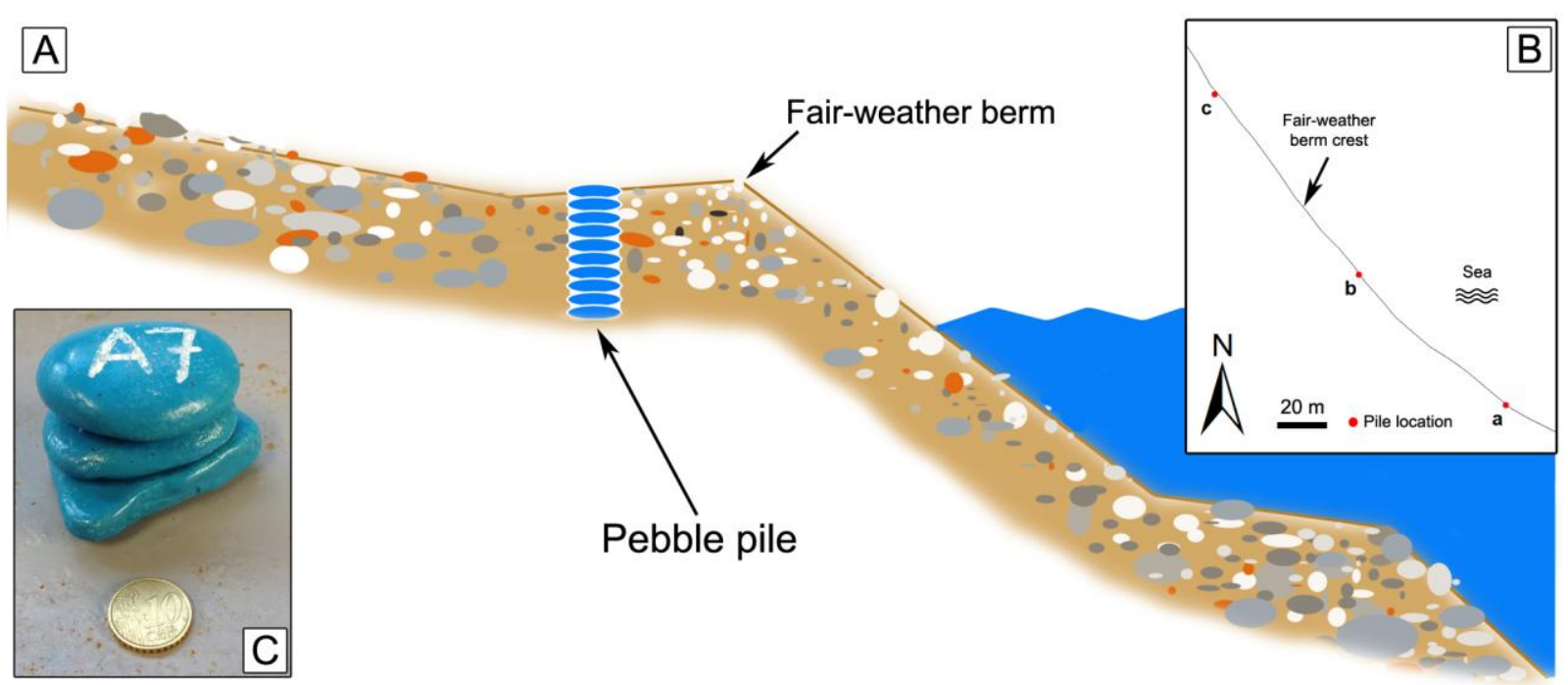

712

713

Figure 8

714 

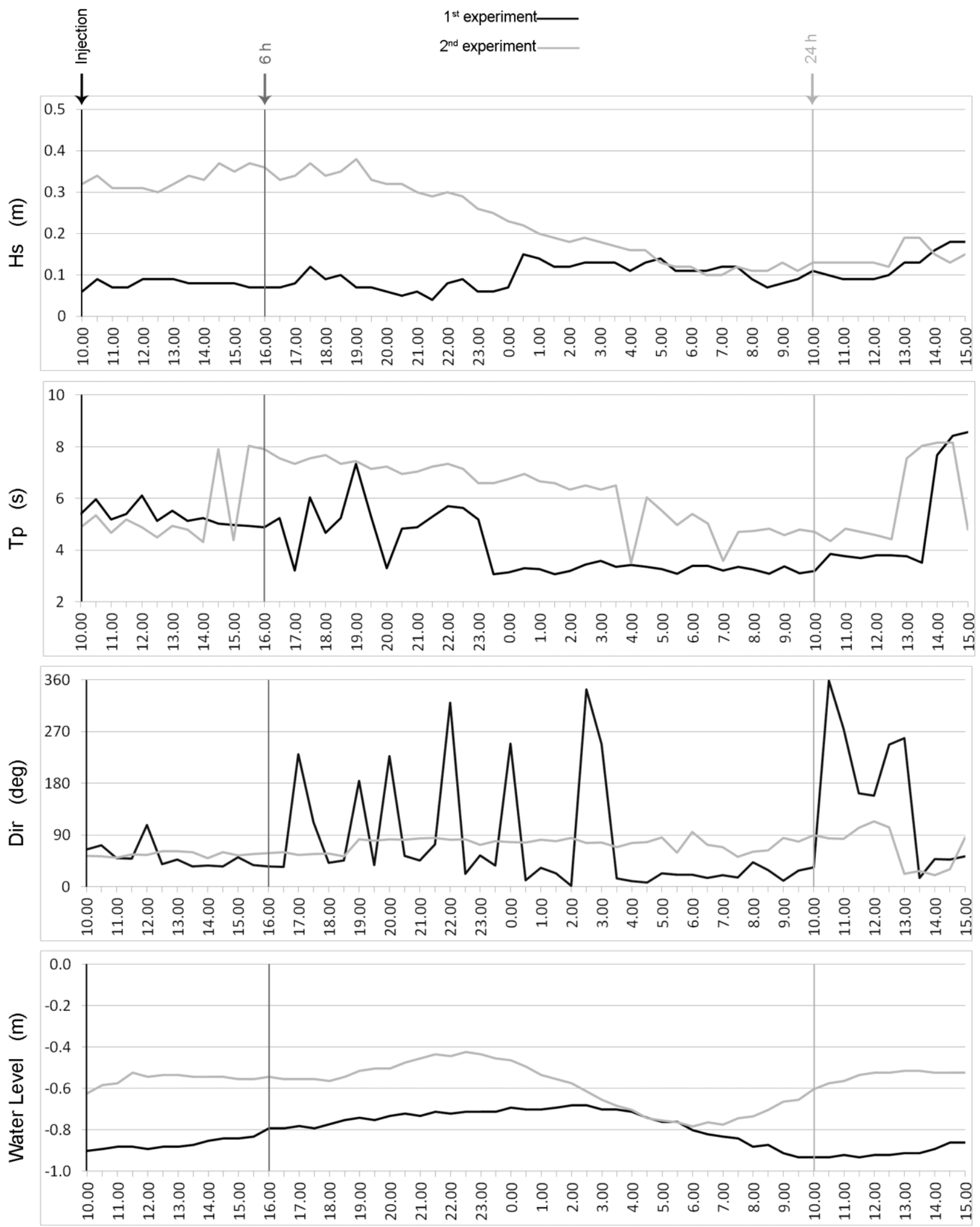

Time (h) 


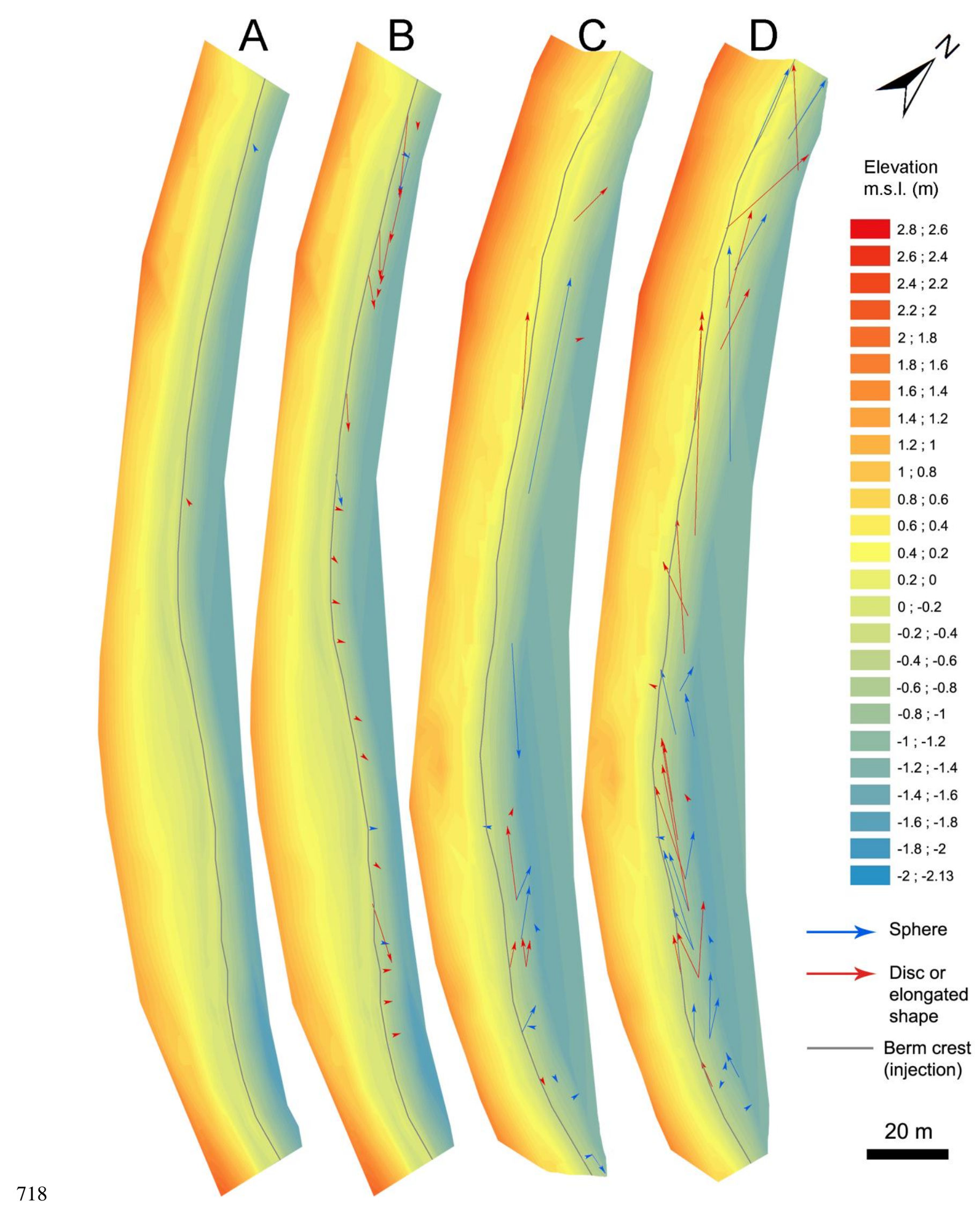




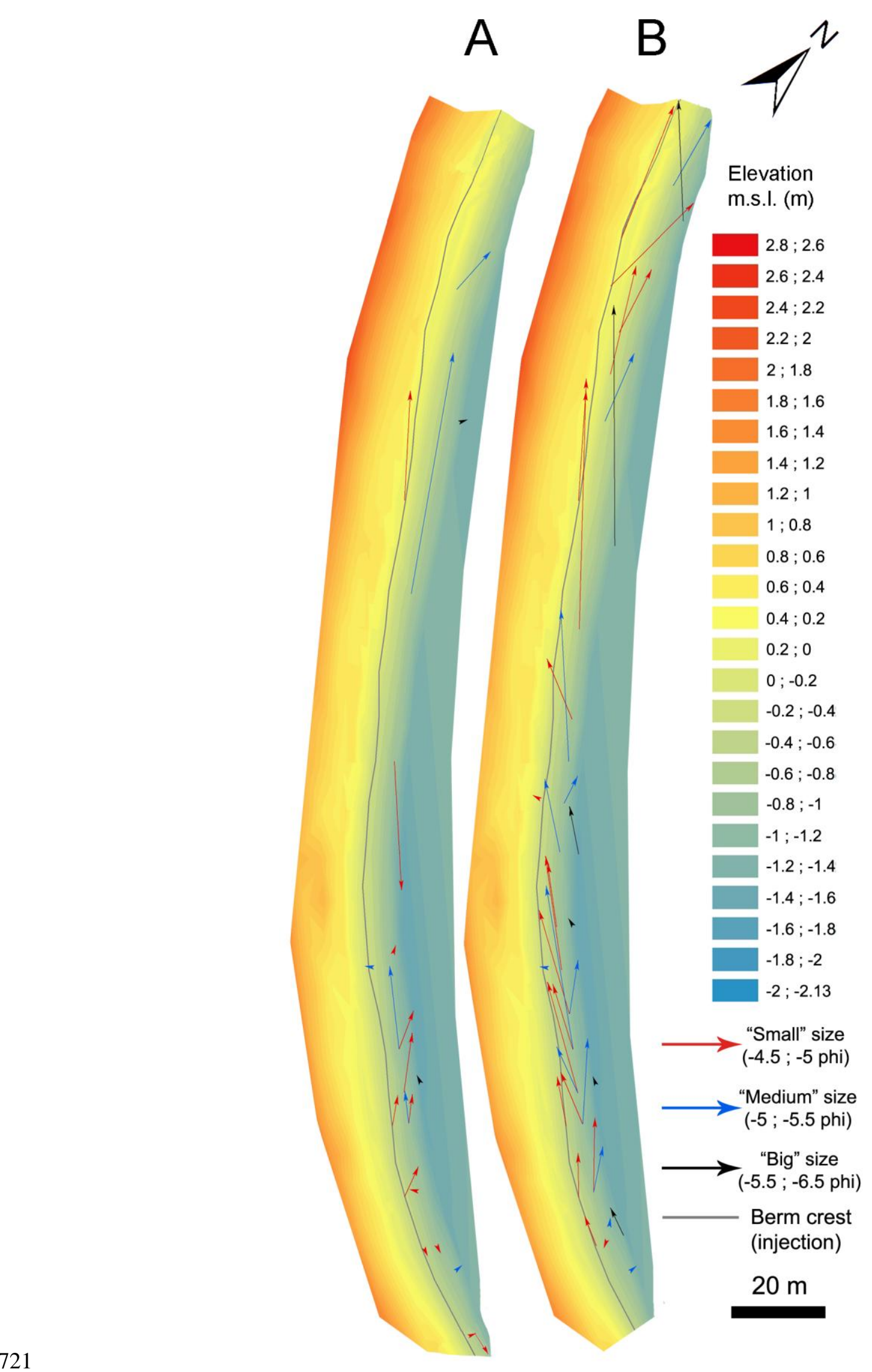



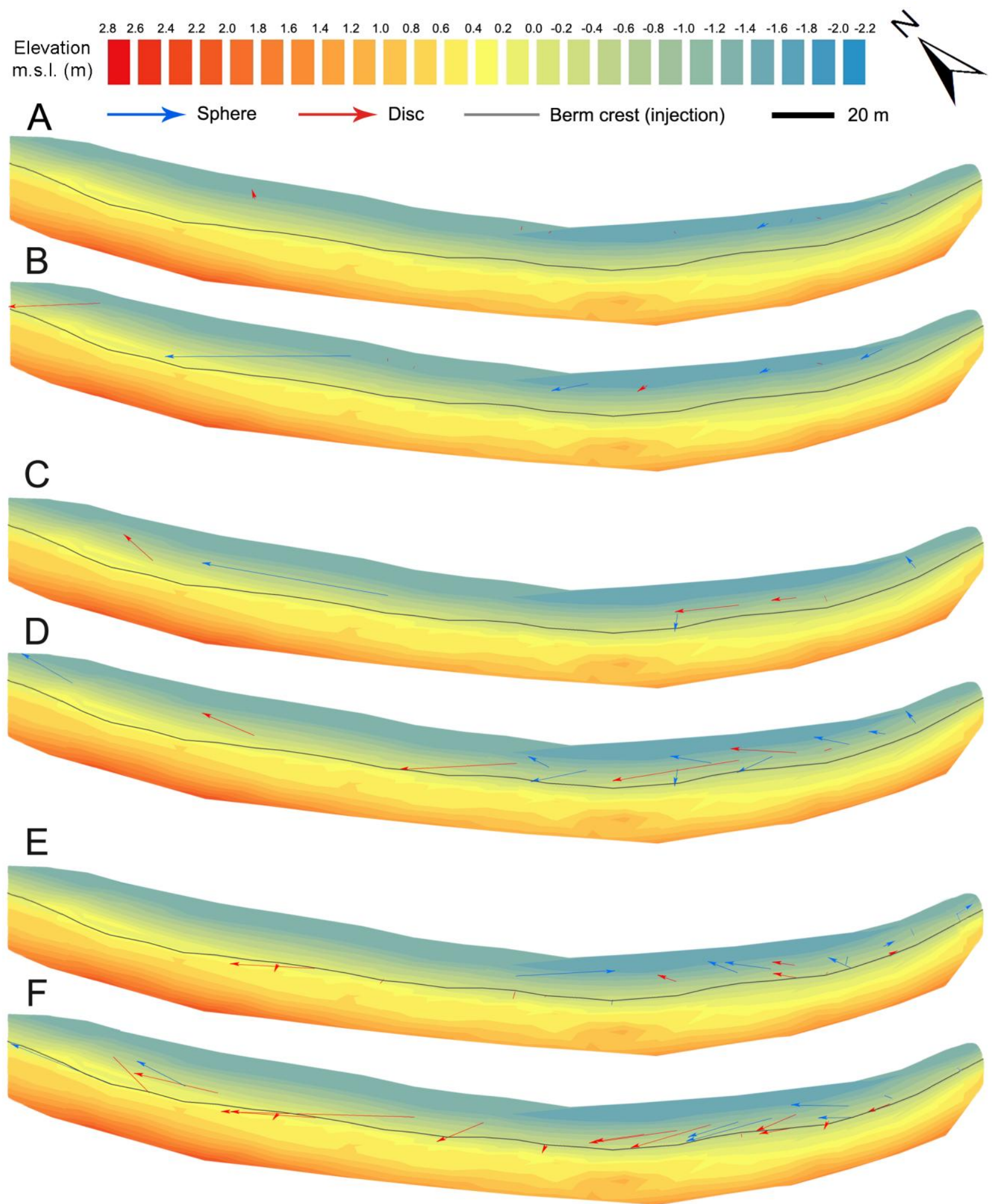
A Tracer displacements ( $1^{\text {st }}$ experiment)

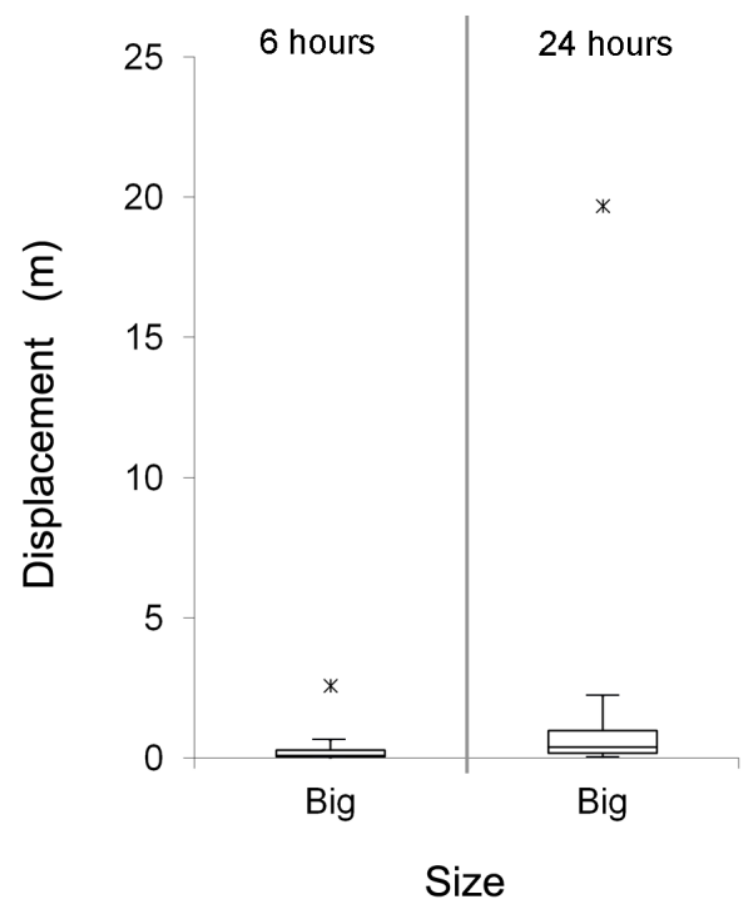

B Tracer displacements ( $2^{\text {nd }}$ experiment)

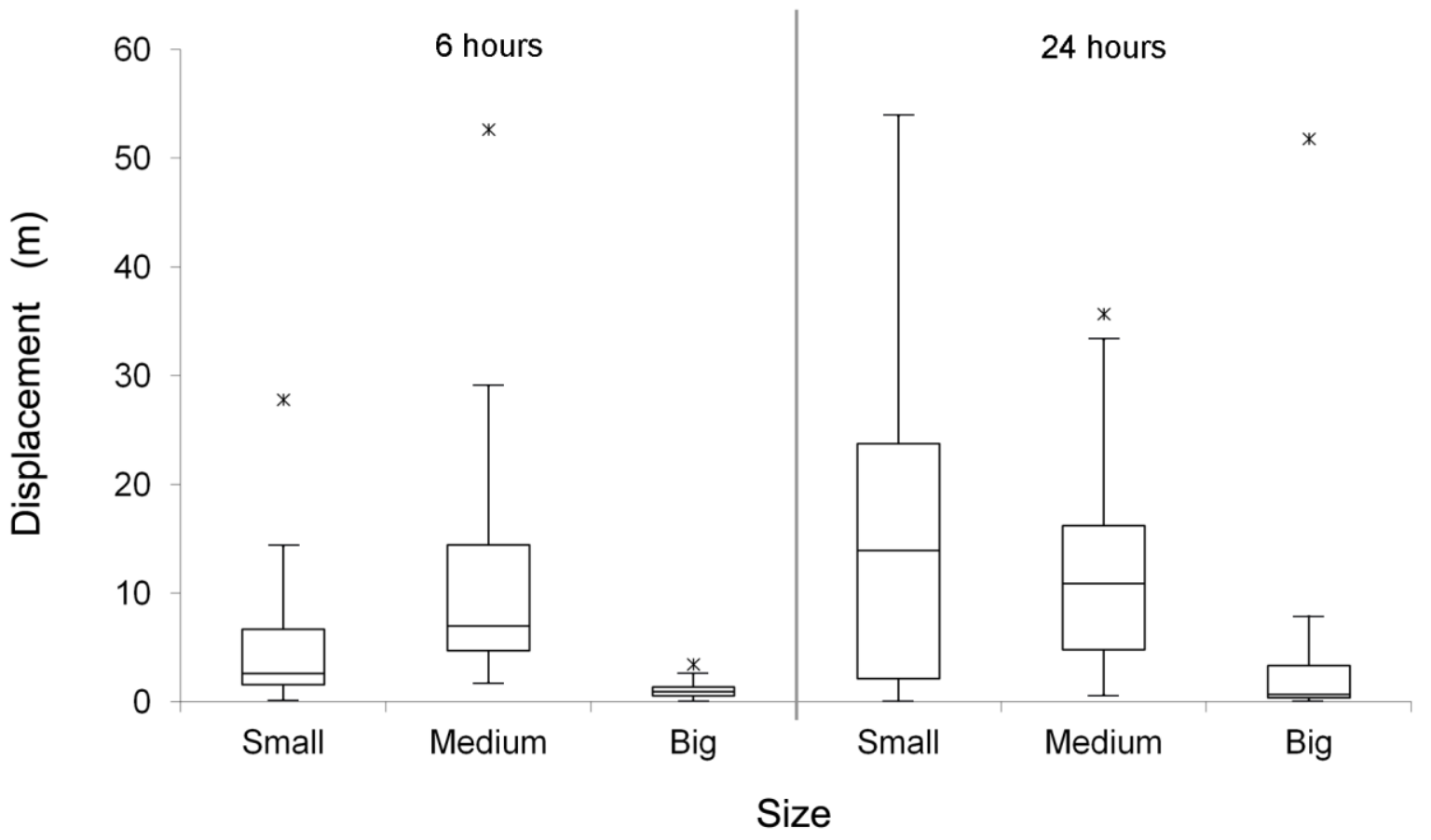


A Tracer displacements ( $1^{\text {st }}$ experiment)

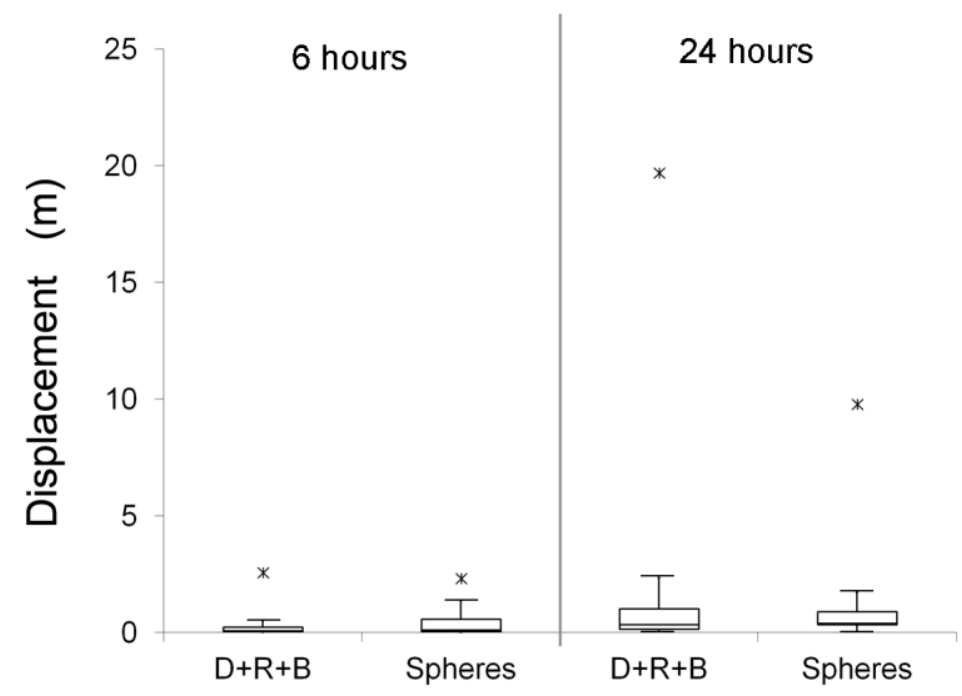

Shape

B Tracer displacements ( $2^{\text {nd }}$ experiment)

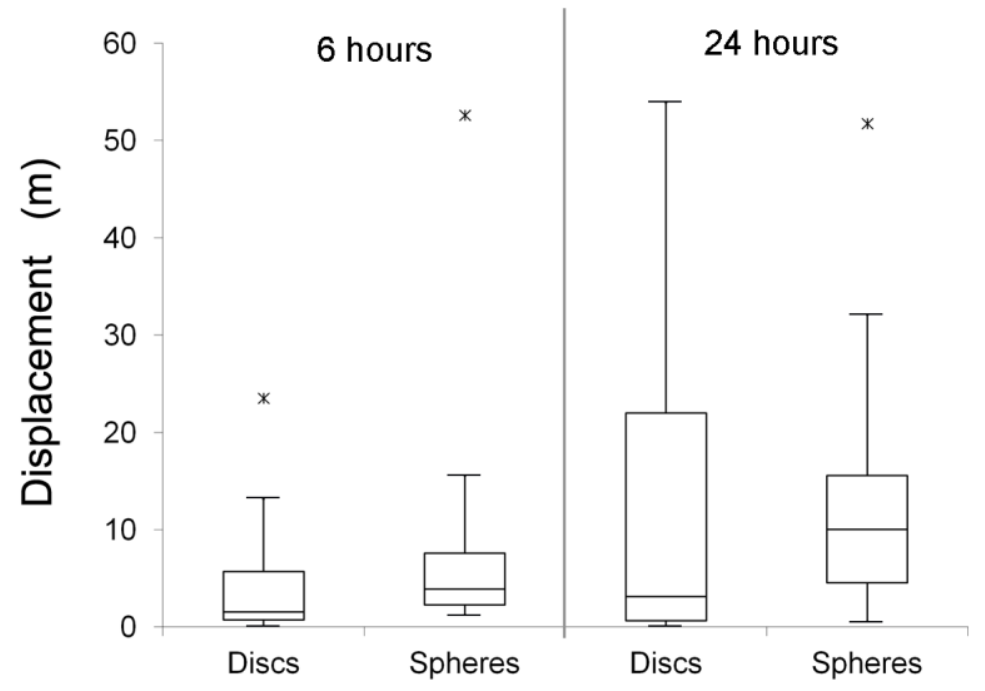

Shape 


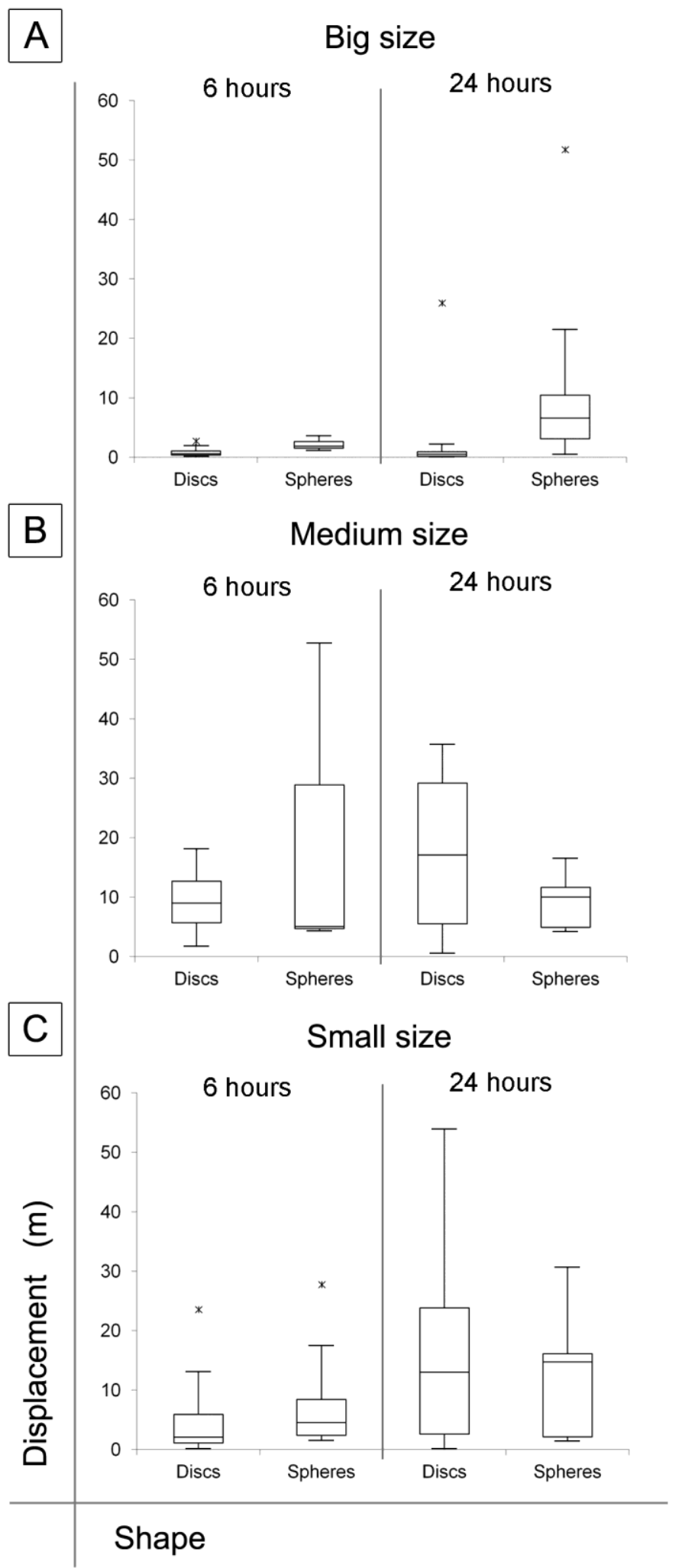




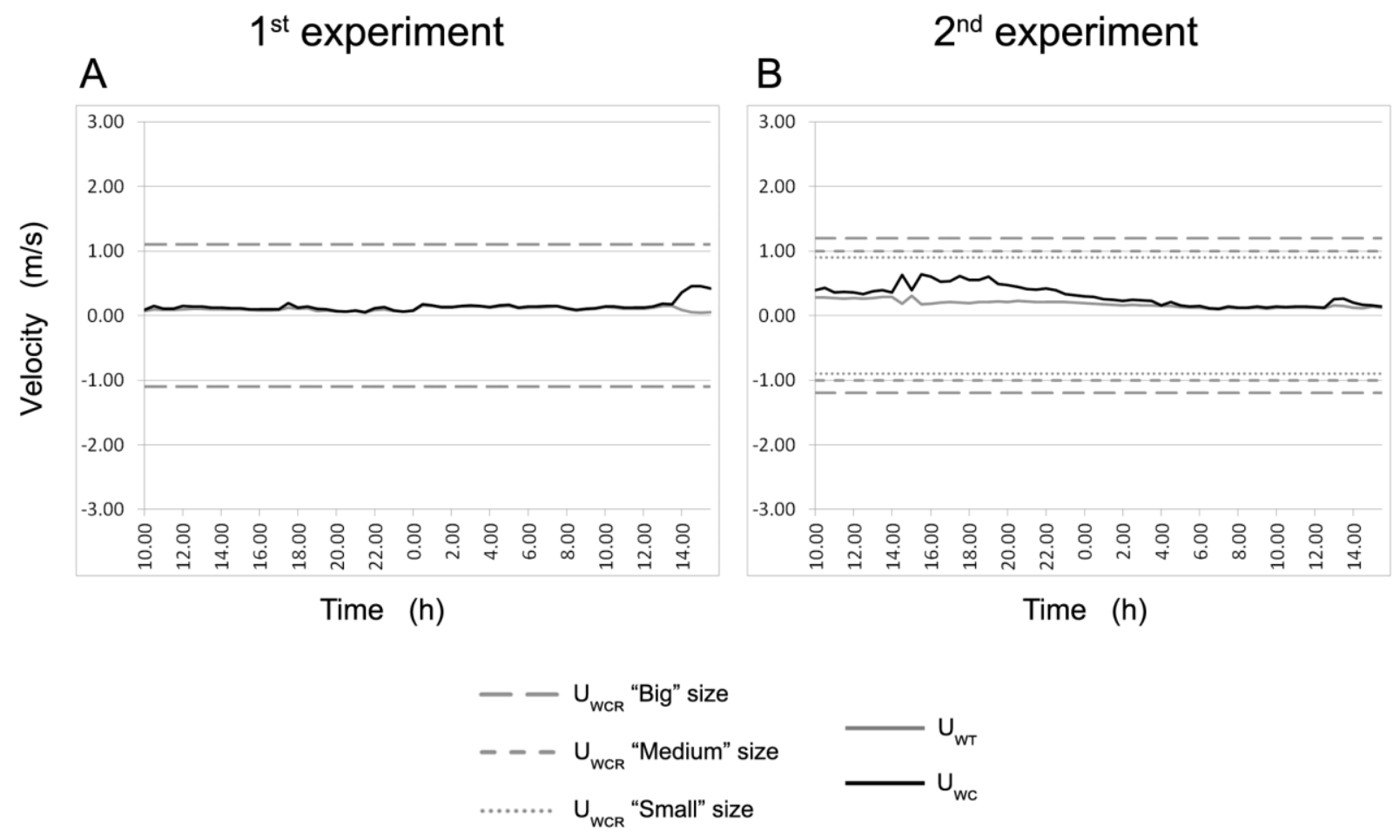

\begin{tabular}{ccccc}
\hline \multirow{2}{*}{$\begin{array}{c}\text { Morphological } \\
\text { feature }\end{array}$} & \multicolumn{2}{c}{ Marked pebbles (size mm) } & \multicolumn{2}{c}{ Beach sediments (size mm) } \\
\cline { 2 - 5 } & $1^{\text {st }}$ experiment & $2^{\text {nd }}$ experiment & $1^{\text {st }}$ experiment & $2^{\text {nd }}$ experiment \\
\hline Berm & 75 & 30 & 6 & 13 \\
\hline Swash & 73 & 37 & 9 & 18 \\
\hline Step & 79 & 71 & 65 & - \\
\hline
\end{tabular}

\begin{tabular}{ccc}
\hline SIZE $(\mathrm{P}<0.05)$ & $2^{\text {nd }}$ exp. $-6 \mathrm{~h}$ & $2^{\text {nd }}$ exp. $-24 \mathrm{~h}$ \\
\hline Small vs. Medium & 0.088 & 0.704 \\
\hline Medium vs. Big & $\mathbf{0 . 0 1 9}$ & 0.142 \\
\hline Small vs. Big & $\mathbf{0 . 0 3 1}$ & 0.058 \\
\hline
\end{tabular}




\begin{tabular}{rcccc}
\hline SHAPE $(\mathrm{P}<0.05)$ & $1^{\text {st }}$ exp. & $1^{\text {st }}$ exp. & $2^{\text {nd }}$ exp. & $2^{\text {nd }}$ exp. \\
$6 \mathrm{~h}$ & $24 \mathrm{~h}$ & $6 \mathrm{~h}$ & $24 \mathrm{~h}$ \\
\hline $\begin{array}{r}\text { Disc } \\
\text { vs. Sphere }\end{array}$ & $\mathbf{0 . 0 2 8}$ & 0.889 & 0.121 & 0.821 \\
\hline $\begin{array}{r}\text { Elongated (D+R+B) } \\
\text { vs. Sphere }\end{array}$ & 0.212 & 0.650 & - & - \\
\hline
\end{tabular}

\begin{tabular}{cccc}
\hline & \multicolumn{2}{c}{ Pile height $(\mathrm{cm})$} & \multirow{2}{*}{ Mixing depth $(\mathrm{cm})$} \\
\cline { 2 - 3 } & Injection & 24 hours & \\
\hline Pile a & 26.15 & 1.5 & 24.65 \\
\hline Pile b & 28.95 & 0 & 28.95 (at least) \\
\hline Pile c & 28.35 & 0 & 28.35 (at least) \\
\hline
\end{tabular}

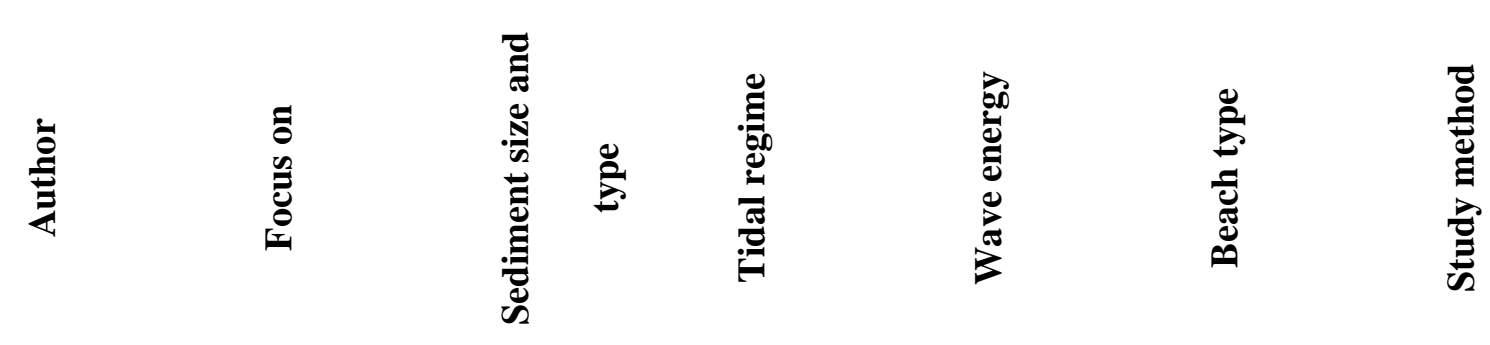

\begin{tabular}{|c|c|c|c|c|c|c|c|c|c|c|c|}
\hline 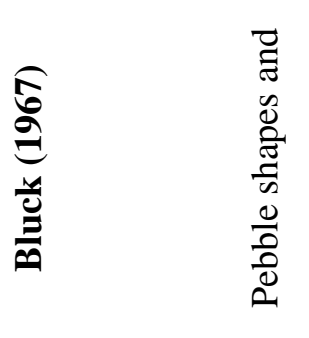 & 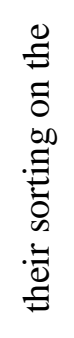 & 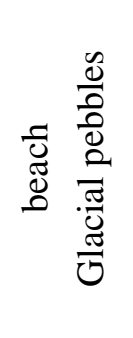 & 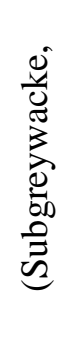 & 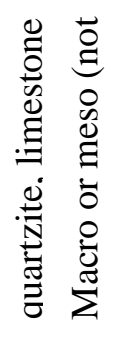 & 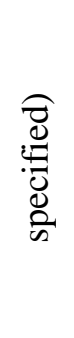 & 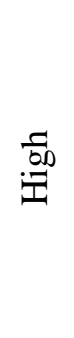 & 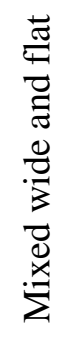 & 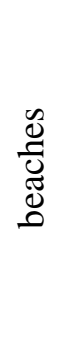 & & 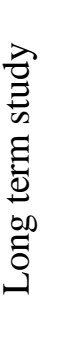 & 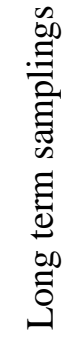 \\
\hline 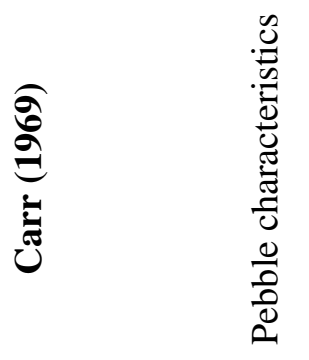 & 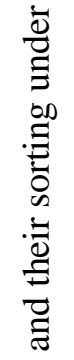 & 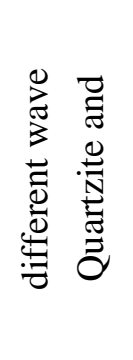 & 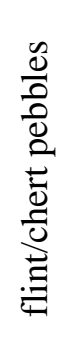 & $\sum_{\substack{0 \\
\Sigma}}^{0}$ & & $\begin{array}{l}\text {.0 } \\
.00\end{array}$ & 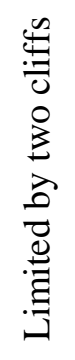 & 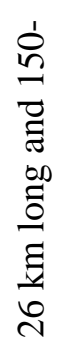 & 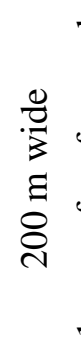 & 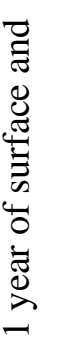 & 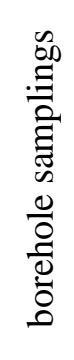 \\
\hline
\end{tabular}



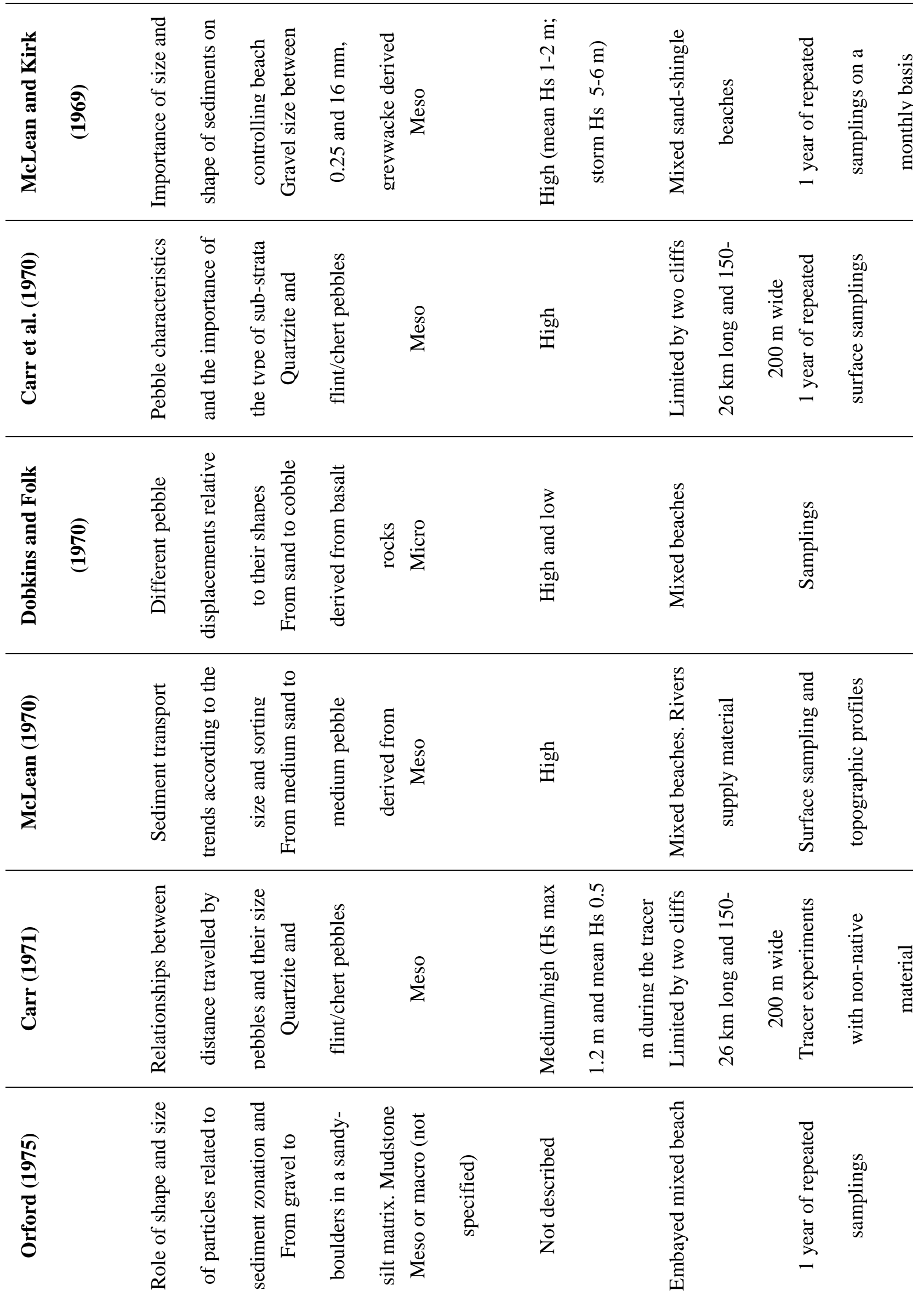

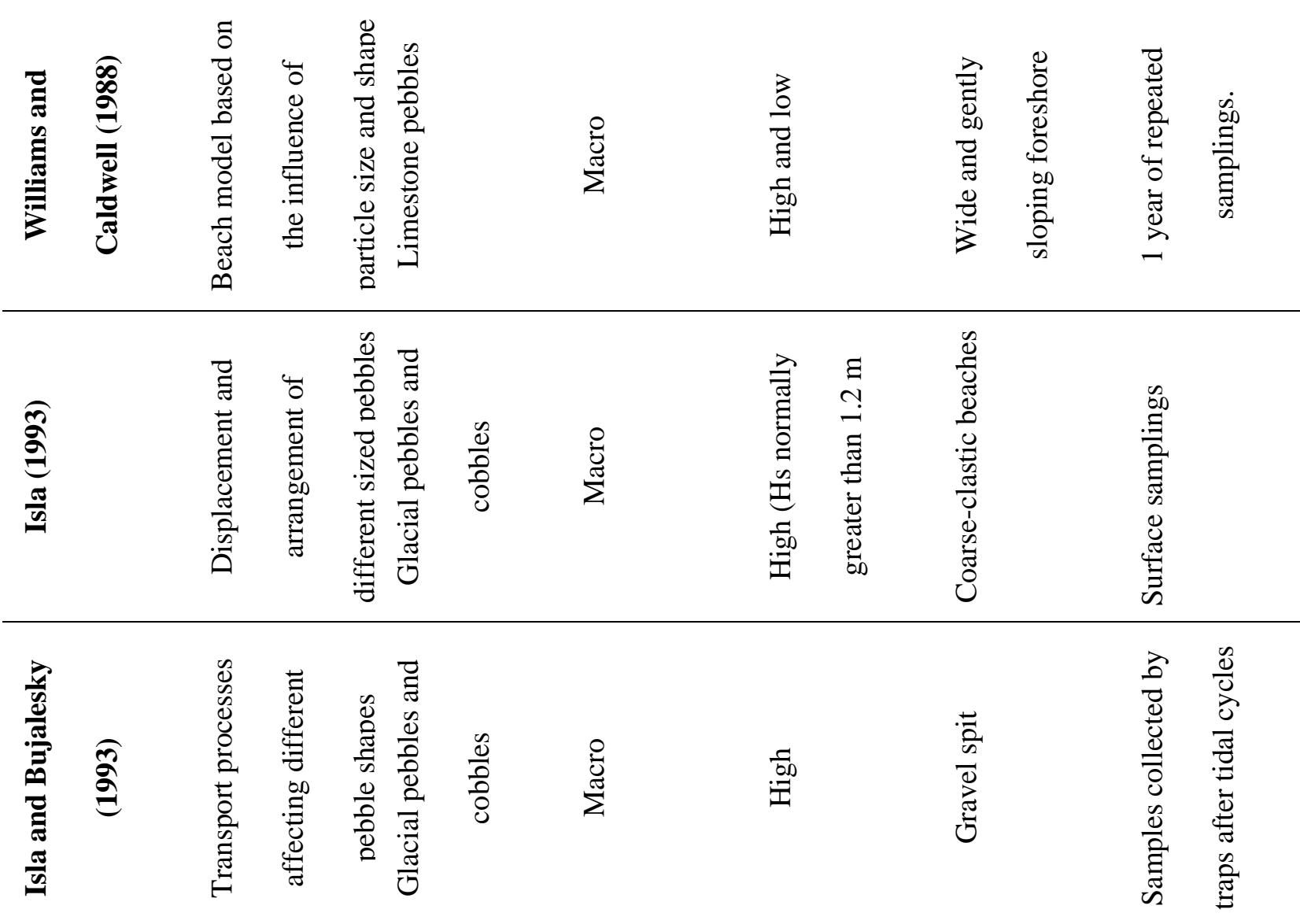

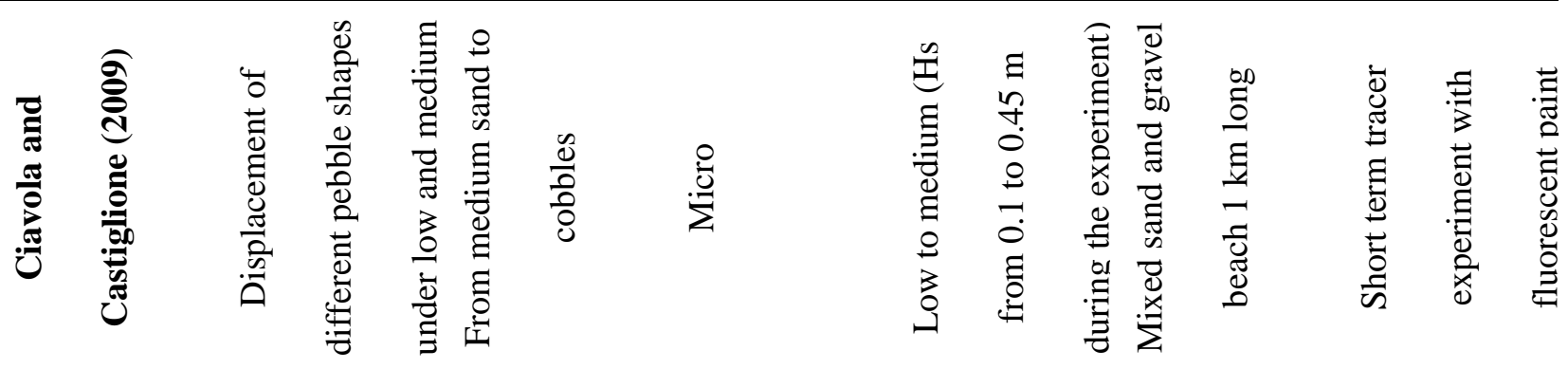

753

754
Table 5 